\title{
Detecting Possible Reduction of the Housing Bubble in Korea for Different Residential Types and Regions
}

\author{
Kyungwon Kim ${ }^{1}$ and Jae Wook Song ${ }^{2, *} \mathbb{B}$ \\ 1 AI Center, Samsung Research, Samsung Electronics Seoul R\&D Campus, Seoul 06765, Korea; \\ kwkim.korea@gmail.com \\ 2 Department of Industrial Engineering, Hanyang University, Seoul 04763, Korea \\ * Correspondence: jwsong@hanyang.ac.kr
}

Received: 24 November 2019; Accepted: 2 February 2020; Published: 7 February 2020

check for updates

\begin{abstract}
The objective of this paper is to detect the arbitrage opportunity and to manage the bubbles in the Korean real estate market based on a binomial American option pricing model with heteroscedasticity. The limitation of previous research where the real options framework was first introduced is its macro-economic implication based on the utilization of the general housing indices. Therefore, in this paper, we extensively apply the model to different residential types and regions. The results suggest that the model can detect the realistic and reasonable trend of housing bubbles and the arbitrage opportunities for different times, residential types, and regions. We also simulate two scenarios to encourage the trades of real estate assets: promotion of early exercise, and the shortened Contract period. Performing arbitrage trading based on these two methods, we discover that both approaches effectively reduce the housing bubbles in all residential types and regions. Specifically, the promotion of early exercise reduces the housing bubble more effectively than the shortened Contract period. Hence, we advocate the utilization of the information obtained from the model to boost the transactions in the Korean real estate market in order to reduce the bubble-related risks and to support sustainable economic growth.
\end{abstract}

Keywords: housing bubble; bubble reduction; real options; American option; binomial tree; residential characteristics

\section{Introduction}

Unlike other financial assets, real estate is a tangible consumer good with durability [1], which can simultaneously provide residential and investment value to the owner. Also, by owning multiple houses, an investor can obtain rental income and profits from their price rise. In this regard, the price of real estate is determined based on the residential value of the property and expectations for future price growth.

However, irrational expectations of price growth can create what is known as the real estate bubble, whose collapse can cause catastrophic damage to the macro-economy, such as the US sub-prime mortgage crisis of 2007-2009. Therefore, measuring and Controlling the size of the bubble in the real estate market is critical for the sustainable growth of the national economy. The Korean real estate market, especially the residential market in Seoul, the capital of the Republic of Korea, has experienced an extreme land boom in the past few years, causing social problems such as generational conflict, being house poor, and a rapid increase in household debt. Based on the belief that the main reason for such a rapid price rise is speculation, the Korean government has utilized various anti-speculative policies, including increasing property taxes and restricting mortgage limits. However, housing prices Continue to rise, as if neglecting the policy. 
Many researchers have discovered the Contributing factors to speculative activity [2,3] and the existence of the housing bubble [4-6] in the Korean real estate market. However, no attempt has been made to analyze the Korean real estate bubble based on the real options approach. In this Context, we proposed a real options model to measure the Korean housing bubble in [7] by utilizing a unique leasing system called the Jeonse, and a binomial tree with heteroscedasticity. Specifically, the real options pricing mechanism can incorporate and simulate the pricing mechanism of the Korean real estate market consisting of the aspects of price dynamics, trading volumes, and its unique leasing system called the Jeonse deposit. In a previous study, we carefully defined the model in terms of the pay-off structures between the landlord and tenant for a Jeonse Contract, which can be seen as a collateral zero-coupon bond. Then, we applied the model to the representative indices of the Korean residential market as a single number, including the Housing Price Index (HPI) and the Jeonse Deposit Index (JDI). Despite its findings, a limitation of this previous work lies in its broad, macro-economic perspective, thus lacking micro-economic implications.

Therefore, in this study, we have expanded the application of the same model in [7] to more specific residential types and regions. Modeling the housing bubbles, defined as the difference between the HPI and JDI, we examine the possibility of bubble reduction by increasing trading volume. Note that the association between the transaction volume and housing price has been discovered in many works of literature. For instance, Berkovec and Goodman (1996) showed the positive correlation between turnover rates and house prices [8], whereas Tu et al. (2009) showed empirical evidence of the connection between price volatility and turnover rates [9]. In summary, analogous to the conclusion of previous studies, we observe the housing bubble reduction for most residential types and regions when an investor considers the Jeonse Contract as an American option, which implies the increase in the number of transactions in the real estate market. Besides, the shortened Jeonse Contract period also can reduce the housing bubble, but not as effectively as the increases in the number of transactions.

\section{Literature Review}

Many studies have been conducted to explain the real estate market and its associated bubbles based on various mathematical models. Since most real estate indicators are in time series, stationary tests were utilized to model the real estate market. However, the prior stationary test is not appropriate when a bubble exists in the market. Hence, extensions of the unit root test with an explosive root have been widely studied and applied for speculation $[1,10,11]$. While the time series approach has the explanatory power to price dynamics, the price of the real estate market, known to be incomplete and inefficient, is not only affected by its previous prices, but also by exogenous factors. In particular, relationships among real estate prices, volume, and market participants have been discovered in most countries. Notably, the decisions of market participants have been found to affect the price dynamics of the real estate market. In this Context, a cash flow analysis can be utilized to understand the decision-making of market participants. Particularly, for optimal investment decisions in the real estate market, a real options approach can provide operating flexibility in decision-making for respondents in various future scenarios $[12,13]$. Furthermore, speculation in the real estate market refers to the existence of an arbitrage opportunity [14]. Note that real options can be used to measure the size of such arbitrage. In this Context, many visions and options-based approaches have been proposed as a risk management mechanism to reduce the market uncertainty [15-17]. Also, the real estate market can be divided into land and building parts, both of which are efficient to be considered as real options in terms of price irreversibility and Continuity [18]. In this Context, many related studies have been published, such as on investor competition and investment timing [19-23], factors affecting real estate cycles [24,25], and decisions in social overhead capital projects [26], which confirm the usefulness of real options in terms of real estate development and urban planning. 
The concept of a real option was introduced by Steward Myers (1977), who proposed a novel decision-making mechanism in terms of expanding, converting, suspending, abandoning, Contracting, and delaying options [27]. It is a well-known fact that the decision based on real options yields more optimal economic values than a simple net present value [28]. Especially in terms of estimating and reducing the bubble in the real estate market, the work of [29] utilized real options to estimate short-term bubbles for the 48 states in the United States. Also, the work of [30] incorporated put option pricing to determine whether the global real estate market was undervalued in 18 countries after the Asian financial crisis, whereas the work of [31] confirmed the undervalued real estate market in the 500 real estate categories in 19 countries through the put option. Furthermore, the works of $[32,33]$ utilized the real option to discover the real estate bubble in Hong Kong and Thailand; the works of [34,35] assessed the appropriate level of land prices in Japan through real options and confirmed the existence of a bubble; and the work of [36] and that of [37] utilized the options approach to identify the real estate bubbles in Latvia and the Czech Republic, respectively. In summary, the options approach can reflect the uncertainty of real estate investors more effectively than the traditional discounted cash flow or net present value analysis [38,39]. In particular, the options theory helps decision-making by providing information regarding optimal investment timing and flexibility in the usage of real estate property.

There are popular models used for option pricing, including the Black-Scholes, differential equations, tree models, Monte Carlo, and optimization methods [40-42]. In particular, the finite difference method [43-49] and bi-/tri-nomial tree approach [50-52] have been widely used due to their computational accuracy and flexibility. Furthermore, GARCH-based models have been popular for their analysis of the volatility of real estate prices. For instance, a GARCH process was utilized in the estimation of volatility based on macro-economic variables [53], high frequency volatility [54], and implementation in the US real estate market [55-58]. Therefore, the GARCH must be included in the options pricing model in the real estate market, where GARCH-based option pricing models have been provided in many studies [59-63]. In this paper, we chose the binomial option pricing model using the GARCH for volatility estimation as a base model to evaluate the real options in the Korean real estate market. Then, we set out to propose a new binomial option pricing model with heteroscedasticity by setting the probabilities of price rise and fall to be equal, which allows for the computation of different increasing and decreasing factors for price rise and fall, as in [7]. The proposed model can keep track of market trends based on new information in the future.

There are also two types of options one can choose: European and American. A European option can be exercised only at maturity, whereas an American option can be exercised at any time before expiration [64]. In the real estate market, a transaction can be terminated at any time before the maturity of the Contract. Also, the uncertainty in the date of the deal's conclusion with the counterpart, the irreversibility of real estate development plans, and the seller's strategic waiting for price rises are frequently observed in the real estate market [65]. In recent studies, the American option has been proven to be valid based on the Martingale theory in estimating the optimal time point for investment under the Wiener process [66,67]. However, the current transaction of the Jeonse Contract in the Korean residential market is close to the European option, since most tenants prefer to fully reside until the Contract expiration date. In particular, when making decisions before the Contract's expiry, both the tenant and landlord are afraid of uncertainty in future housing prices. Thus, if bubble-related information can be provided, an investor may be able to make informed decisions before the end of the Contract. It implies that the market participants can consider the transactions in the Korean real estate market as an American option. In this Context, we compare the differences between the values of European and American options for different residential types and regions in Korea to examine the decrease in the housing bubble. 


\section{Data \& Methods}

\subsection{Data}

The data used in this research consists of 180 observations for the monthly House Price Index (HPI), the Jeonse Deposit Index (JDI), and the monthly market interest rate (IR) from 1 January 2004 to 31 December 2017. The data was obtained from the Economic Statistics System (ECOS) of the Bank of Korea. The ECOS provides the HPI and JDI indices for the entire real estate market and sub-indices for different residential types (apartments, detached houses, and row houses) and regions. The names and corresponding abbreviations for the regions of the Republic of Korea are described in Figure 1. Specifically, the HPI and JDI for each residential type involve different regional data based on the regions provided in Figure 1 as follows:

- Apartments (13)

- $\quad$ SEL, NSEL, SSEL, 6MC, GYG, GAW, CCB, CCN, JLB, JLN, GSB, GSN, Non-Metropolitan Areas (NMA, all regions except the SEL, 6MC, and GYG)

- $\quad$ Detached and Row Houses (6)

- $\quad$ SEL, NSEL, SSEL, 6MC, GYG, NMA

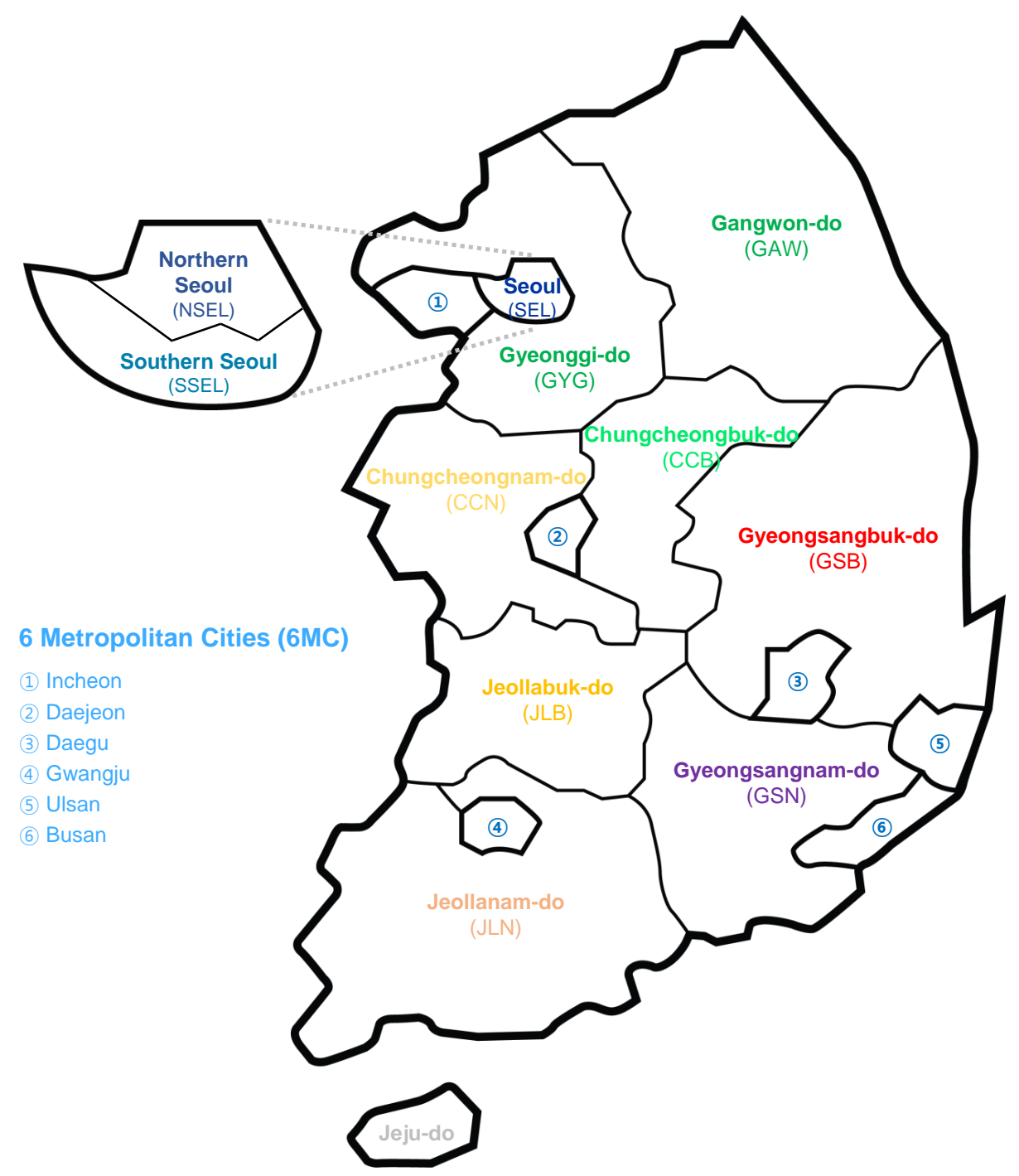

Figure 1. Regional Map of the Republic of Korea corresponding to the HPI and JDI dataset. 


\subsection{Real Options Framework}

\subsubsection{Arbitrage and Real Option Setting}

Geltner and Miller [68] stated that the efficacy of the real options or financial options depends on their application domains. However, the real estate market in Korea, which seems suitable for the real options valuation, can be modeled as a financial option due to its expiration date and fair-trade payoff structures [7]. The only difference is the presence of arbitrage. The financial market converges on a no-arbitrage condition based on the law of one price [69], but the real estate market in Korea is not actively traded enough to satisfy such conditions. It has also been profoundly affected by the changes in housing policies. In the short term, the real estate markets will be traded at fair prices without arbitrage opportunities, but in the long term, it will eventually possess arbitrage opportunities. In other words, it is necessary to confirm that the increase in transactions can reduce the chance of arbitrage and eventually reduce the size of the housing bubble. Therefore, we confirmed the existence of arbitrage and elimination of arbitrage due to active transactions based on the algorithm presented in [7]. Furthermore, in this paper, we extend the same approach to different types of housing and regions in Korea. Note that the detailed explanation of the real estate market in Korea, especially the system called the Jeonse, can be found in [7].

\subsubsection{Mechanics of the Binomial Option Pricing Model with Heteroscedasticity}

The real options approach in this paper utilizes the same binomial option pricing model with heteroscedasticity introduced in [7]. Note that the real options framework is briefly summarized in this paper to avoid redundancy from our previous work. A more detailed explanation can be found in Section 4 in [7]. Firstly, the mapping of variables for a binomial tree in terms of a financial option is summarized in Table 1. As stated in [7], a Jeonse Contract can be considered as a zero-coupon collateral bond. At the beginning of the Jeonse Contract, a tenant typically pays $40 \%$ to $80 \%$ of the value of a property as an agreed up-front deposit to the landlord. Then, at the maturity date, a landlord reimburses the nominal value of the deposit to the tenant. Note that a principal default risk exists since there is no obligation on the landlord to lock the deposit in an escrow account [70]. When the landlord fails to fulfill the obligation, the ownership of the property is transferred to the tenant. There are two options traded for a single Jeonse Contract for different stages.

- First stage: From the landlord's Contract notice in the market to the Contract date.

- Second stage: From the Contract date to maturity of the Contract.

Table 1. Mapping of the variables of options between a financial market and the Korean real estate market.

\begin{tabular}{ccc}
\hline Financial Market & Variable & Real Estate Market \\
\hline Underlying asset price & $S$ & Housing Purchase Index (HPI) \\
Strike price & $K$ & Jeonse Deposit Index (JDI) \\
Time to maturity & $T$ & Length of Contract \\
Volatility of underlying asset & $\sigma$ & Volatility of HPI \\
Risk-free rate of return & $R$ & Time value of money on HPI/JDI \\
Price of option & $V$ & Present value of a future spreads \\
No & Arbitrage & Yes \\
\hline
\end{tabular}

In the first stage, the tenant can be considered as possessing a long call and short put options simultaneously. Note that the price of the property and corresponding deposit can be seen as the underlying asset and strike price, respectively. In Contrast, the landlord can be considered as possessing a long put and short call options. In the second stage, the positions of the tenant and landlord are switched. That is, a Jeonse system itself Contains two Contracts where the Contract can be expressed as a zero-coupon bond, since the payoffs of the tenant and landlord can be completely hedged during 
the entire period. The variable $V$ in the real estate market refers to the present value of the payoffs during a Jeonse Contract, which can be seen as the sum of a Jeonse Contract's opportunity cost and the time value of the underlying asset (house). Again, the time taken to maturity, $T$, is the length of a Jeonse Contract, which is usually two years.

The binomial tree-based valuation used in this paper has been widely studied in decision-making problems [71-73]. Furthermore, a trinomial tree has also been studied for accurate valuation [74]. Similar to the approach in [75], whose trinomial tree incorporates the changing volatility, we also proposed an algorithm for the binomial option pricing model with heteroscedasticity in [7]. The model can be summarized as follows. At first, the house price, $S_{t}$, paying no dividend at time $t$ under the physical probability measure $P$, is randomly distributed, whose stationary return series follows the geometric Brownian motion. Let $\mu_{t}$ and $\sigma_{t}$ be the drift and diffusion terms changing with respect to time; then, $W_{t}$ is a standard Brownian motion (i.e., Wiener process) in a $P$-measure standard Brownian motion. Applying the heuristic rule based on Ito's Lemma and $\left(\frac{d S_{t}}{S_{t}}\right)^{2}=\sigma_{t}^{2} d t$, we obtain $d \ln \left(S_{t}\right)$ as follows.

$$
\begin{aligned}
\frac{d S_{t}}{S_{t}} & =\mu_{t} d t+\sigma_{t} d W_{t}^{P} \\
d \ln \left(S_{t}\right) & =\frac{d S_{t}}{S_{t}}-\frac{1}{2}\left(\frac{d S_{t}}{S_{t}}\right)^{2} \\
d \ln \left(S_{t}\right) & =\left(\mu_{t}-\frac{1}{2} \sigma_{t}^{2}\right) d t+\sigma_{t} d W_{t}^{P}
\end{aligned}
$$

Based on the Girsanov theorem, $S_{t}$ has no arbitrage opportunity when an equivalent martingale measure exists. Therefore, a measure change from $P$ to $Q$ does not change the diffusion component $\sigma_{t} d W_{t}$ when drift term $\mu_{t}$ converges to zero [76]. Under this measure, there is no compensation for risk, and $Q$ is also called the risk-neutral measure (or risk-adjusted measure $Q$ ). In this regard, $W_{t}^{Q}$ under the risk-neutral Q-measure is the standard Brownian motion, where the mean and variance of the change of a measure of $d \ln \left(S_{t}\right)$ are as follows:

$$
\begin{aligned}
d \ln \left(S_{t}\right) & =\left(\mu_{t}-\frac{1}{2} \sigma_{t}^{2}\right) d t+\sigma_{t} d W_{t}^{Q} \\
E^{Q}\left[d \ln \left(S_{t}\right)\right] & =\left(\mu_{t}-\frac{1}{2} \sigma_{t}^{2}\right) d t \\
\operatorname{Var}^{Q}\left[d \ln \left(S_{t}\right)\right] & =\sigma_{t}^{2} d t .
\end{aligned}
$$

Since $d \ln S_{t}=\ln \left(S_{t+1} / S_{t}\right)$ in a binomial tree, the mean and variance can be derived under the risk neutral measure as follows:

$$
\begin{aligned}
E^{Q}\left[d \ln \left(S_{t}\right)\right] & =P_{u} \ln \left(u_{t}\right)+P_{d} \ln \left(d_{t}\right) \\
\operatorname{Var}^{Q}\left[d \ln \left(S_{t}\right)\right] & =P_{u} P_{d}\left[\ln \left(\frac{u_{t}}{d_{t}}\right)\right]^{2} .
\end{aligned}
$$

where $u_{t}$ and $d_{t}$ indicate the proportions of the upward and downward movement of $S_{t}$, respectively.

In a traditional binomial tree model, the risk-neutral probabilities for upward and downward movements, $P_{u}$ and $P_{d}$, can be obtained by fixing the values for $u_{t}$ and $d_{t}$, such that:

$$
\begin{aligned}
& P_{u}=\left(e^{r \Delta t}-d\right) /(u-d) \\
& P_{d}=1-P_{u} .
\end{aligned}
$$

However, Equation (9) requires knowledge on the evolutions of the interest rate, $r$ in the future, which is unrealistic. Instead, we suggest setting $P_{u}=P_{d}=1 / 2$ to compute the time-varying $u_{t}$ and $d_{t}[7,75]$. There are two reasons for why the fixed probability should be $1 / 2$. The first reason is that 
the probability of a rise or fall in house prices in the future is unknown. It implies that the probability of price rise and fall is the same at the next point, such as a random walk. The second reason is that the fixed probability allows the changes in $u_{t}$ and $d_{t}$ for different $t$, which can keep track of market trends based on new information in the future. Note that the disadvantage of our approach is its much longer computation time. In this Context, the proposed model can yield $u_{t}>d_{t}>1\left(1>u_{t}>d_{t}\right)$ for a rising (falling) trend, whereas the traditional model usually assumes $u_{t}>1$ and $1>d_{t}$. Note that the proposed binomial tree has a disadvantage in longer computation time due to the increase of the number of nodes by $2^{t}$ as the time, $t$, moves one step [71]. However, the proposed binomial tree has the advantage of reflecting the trend and variance of the underlying asset more flexibly [7].

For small $d t$ in $E\left[d \ln \left(S_{t}\right)\right]$ and $\operatorname{Var}\left[d \ln \left(S_{t}\right)\right]$, we can obtain the equations for $u_{t}$ and $d_{t}$ as follows:

$$
\begin{aligned}
\frac{1}{2} \ln \left(u_{t}\right)+\frac{1}{2} \ln \left(d_{t}\right) & =\left(\mu_{t}-\frac{1}{2} \sigma_{t}^{2}\right) \Delta t \\
\ln \left(u_{t} d_{t}\right) & =2 v_{t} \Delta t \\
v_{t} & =\mu_{t}-\frac{1}{2} \sigma_{t}^{2} \\
u_{t} d_{t} & =\exp \left(2 v_{t} \Delta t\right) .
\end{aligned}
$$

Since the probability of increases and decreases in house price is fixed to $1 / 2$, the proposed binomial tree can be derived by applying the returns and the pre-estimated volatility at each time-point by setting the $u_{t}$ and $d_{t}$ as follows:

$$
\begin{aligned}
& u_{t}=\exp \left(v_{t} \Delta t+\sigma_{t} \Delta t\right) \\
& d_{t}=\exp \left(v_{t} \Delta t-\sigma_{t} \Delta t\right) .
\end{aligned}
$$

where the volatility, $\sigma_{t}$, is estimated based on the GARCH model. In particular, the likelihood, autocorrelation, limit theory, and stationary properties of $\operatorname{GARCH}(1,1)$ have been widely studied [77-81] in terms of volatility forecasting [82]. The estimation process of the $\operatorname{GARCH}(1,1)$ model can be defined as follows:

$$
\begin{aligned}
r_{t} & =\sigma_{t} \epsilon_{t} \\
\epsilon_{t} & \sim N(0,1) \\
\sigma_{t}^{2} & =\omega+\alpha \epsilon_{t-1}^{2}+\beta \sigma_{t-1}^{2}
\end{aligned}
$$

where $r_{t}=\ln \left(S_{t}\right)-\ln \left(S_{t-1}\right)$ indicates the log-return of HPI, and $\epsilon_{t}$ indicates white noise based on a standard normal distribution. If heteroscedasticity exists in the return series of HPI, we can reflect the heteroscedasticity in the volatility and time-varying $u_{t}$ and $d_{t}$ by implementing $\sigma_{t}$ obtained from the GARCH model estimation into Equations (15) and (16).

Lastly, we define the bubble as the spread between the HPI and JDI throughout the paper, since the JDI only implies the current residential value of a house. In Contrast, the HPI consists of the residential value and the expectation on price rise in the future. Based on the definition of a bubble and Table 1 , the real options framework can be reinterpreted as follows. If the bubble, $S-K$, generated for each future scenario in the binomial tree is converted to the present value, the option premium $V$ can be regarded as the size of the bubble in the current market. In other words, the bubble we define in this paper represents the expectation of the future value of real estate prices. According to the bubble statistics of the Korean housing market based on the general indices of HPI and JDI in [7], we observed $V>0$ in most cases, but $V<0$ at some economic crises. Similarly, we examined simulations, like whether the size of $V$ computed from the real options framework could be reduced under certain conditions. For instance, if a decrease in the bubble is observed, it implies that the size of the bubble in the housing price is irrationally large. 


\subsection{Data Exploration}

\subsubsection{Indices and Spreads}

Before applying the real options framework, we examined the spread between the HPI and JDI, which can also be considered as a bubble of a real estate property, as explained in [7]. Figure 2 shows the evolutions of the price series of HPI, JDI, and IR for three different residential types based on their average values. All the HPI and JDI in apartments, as well as detached and row houses show an increasing pattern with respect to time. The spread is most consistent in the detached house, whereas those of the apartment and row house are changing according to the market condition. Meanwhile, the spread is the largest in all residential types during the global financial crisis with the highest IR, and the spread steadily decreased after the global financial crisis.

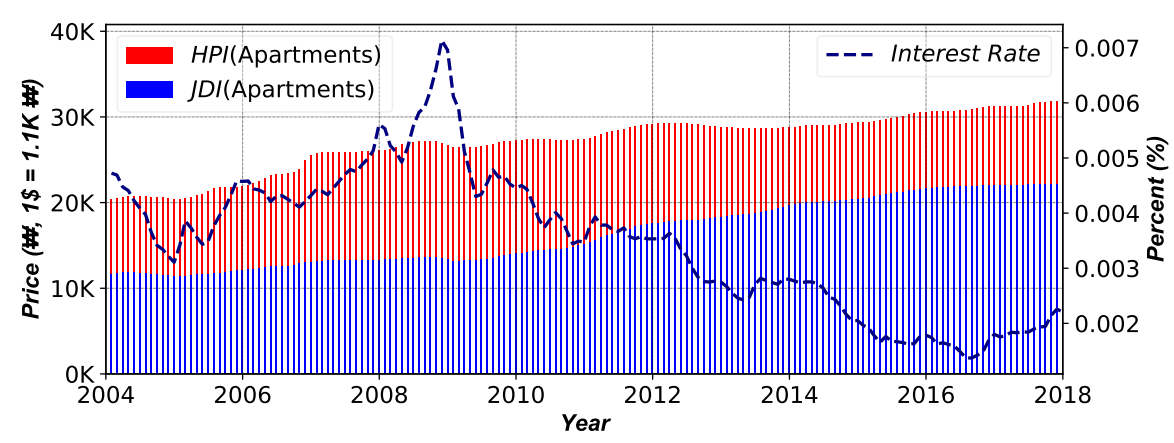

(a) Apartments

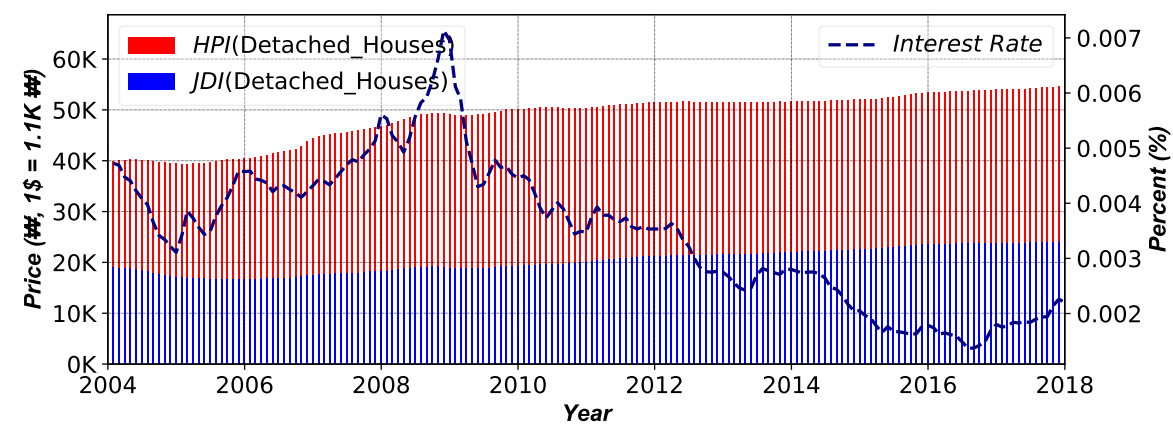

(b) Detached Houses

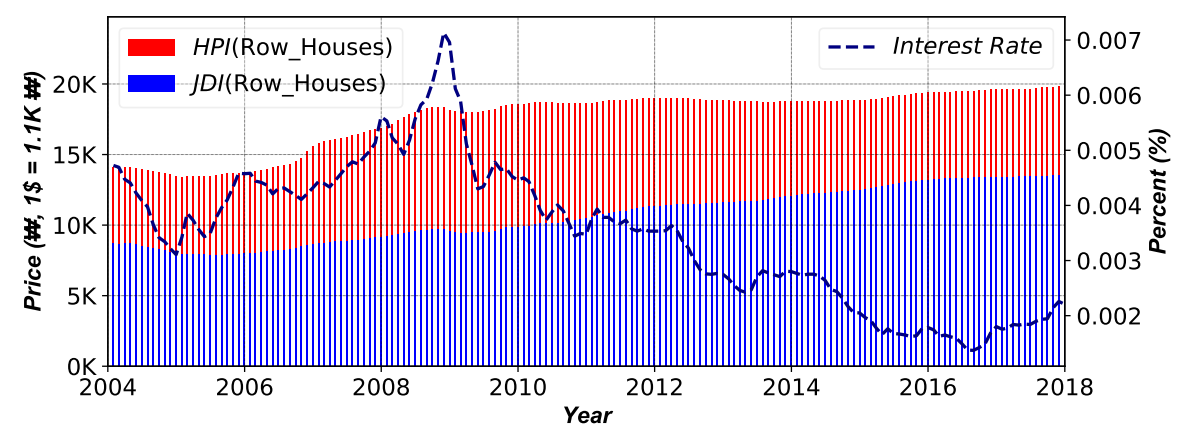

(c) Row Houses

Figure 2. Evolutions of the price series of aggregate HPI, JDI, and interest rates for different residential types. 
Table 2 summarizes the descriptive statistics of the HPI and JDI for three residential types. The means (standard deviations) of the HPI of the apartment, and the detached and row houses are approximately 275(40), 492(51), and 178(22) million Korean Won (KRW), respectively. On the other hand, those numbers of the JDI are 168(39), 206(25), 109(20), respectively. All residential types exhibit a higher HPI than JDI, where the JDI is roughly $40 \%$ to $60 \%$ of the HPI. The distribution of the HPI is skewed left in all three types. The distribution of the JDI is skewed right in apartments and detached houses, whereas it is skewed left in row houses. In the case of kurtosis, all values are negative, so that the distributions of HPI and JDI have lighter tails with a flatter peak than the normal distribution.

Table 2. Descriptive statistics for the price series of HPI and JDI indices $(1 \$=1100 \mathrm{~K} R W)$.

\begin{tabular}{lllllll}
\hline & $\begin{array}{l}\text { Apartments } \\
\text { (HPI) }\end{array}$ & $\begin{array}{l}\text { Apartments } \\
\text { (JDI) }\end{array}$ & $\begin{array}{l}\text { Detached_Houses } \\
\text { (HPI) }\end{array}$ & $\begin{array}{l}\text { Detached_Houses } \\
\text { (JDI) }\end{array}$ & $\begin{array}{l}\text { Row_Houses } \\
\text { (HPI) }\end{array}$ & $\begin{array}{l}\text { Row_Houses } \\
\text { (JDI) }\end{array}$ \\
\hline Mean & $27,504.10$ & $16,792.87$ & $49,197.73$ & $20,566.24$ & $17,783.43$ & $10,873.09$ \\
Stdev & 3957.08 & 3966.40 & 5068.73 & 2525.89 & 2183.69 & 1979.84 \\
Skewness & -0.26 & 0.08 & -0.5 & 0.03 & -0.85 & -0.03 \\
Kurtosis & -1.04 & -1.64 & -0.59 & -1.35 & -0.57 & -1.43 \\
\hline
\end{tabular}

Note: The unit of the mean and standard deviation(Stdev) is ten thousand KRW.

More detailed information regarding the HPI and JDI can be further extended to each residential type for each region. Figure 3 illustrates the evolutions of the HPIs and JDIs of apartments in different regions. The y-axis (price) of both the HPI and JDI is set to the same scale. In general, the JDI is notably less than the HPI. For each index, the HPI and JDI of each region do not overlap each other at a high price range, whereas the prices overlap in the relatively low price range that mostly consists of NMA. Also, the overall upward trend is similar in all regions, but the fluctuating trends in SEL, NSEL, SSEL, and GYG are highly correlated than those of the others. The descriptive statistics of each residential type for each region are summarized in Tables 3 and 4.

Table 3. Descriptive statistics for the apartment's price series of HPI and JDI indices in different regions.

\begin{tabular}{|c|c|c|c|c|c|c|c|}
\hline \multicolumn{8}{|c|}{ (a) House Price Index } \\
\hline & SEL & NSEL & SSEL & $6 \mathrm{MC}$ & GYG & GAW & ССВ \\
\hline Mean & $62,638.21$ & $46,736.65$ & $76,030.43$ & $21,739.38$ & $31,545.54$ & $14,406.90$ & $13,389.09$ \\
\hline Stdev & 7878.61 & 6149.53 & 9351.33 & 3960.62 & 3408.66 & 2107.30 & 2797.54 \\
\hline Skewness & -0.68 & -0.74 & -0.61 & 0.08 & -1.35 & 0.14 & 0.06 \\
\hline \multirow[t]{2}{*}{ Kurtosis } & 0.5 & -0.06 & 0.9 & -1.62 & 0.56 & -1.69 & -1.75 \\
\hline & $\mathrm{CCN}$ & JLB & JLN & GSB & GSN & NMA & \\
\hline Mean & $15,676.47$ & $14,939.69$ & $13,982.16$ & $13,911.59$ & $17,121.54$ & $15,435.61$ & \\
\hline Stdev & 2240.56 & 2827.86 & 1948.61 & 2529.06 & 3457.71 & 2784.64 & \\
\hline Skewness & 0.2 & -0.33 & -0.21 & 0.28 & -0.13 & -0.06 & \\
\hline Kurtosis & -1.8 & -1.62 & -1.73 & -1.55 & -1.85 & -1.8 & \\
\hline \multicolumn{8}{|c|}{ (b) Jeonse Deposit Index } \\
\hline & SEL & NSEL & SSEL & $6 \mathrm{MC}$ & GYG & GAW & ССВ \\
\hline Mean & $32,992.25$ & $26,667.69$ & $38,360.04$ & $15,137.67$ & $18,904.15$ & $11,085.44$ & 9809.98 \\
\hline Stdev & 8294.27 & 6577.82 & 9790.66 & 3452.62 & 4779.61 & 2124.48 & 2491.46 \\
\hline Skewness & 0.25 & 0.25 & 0.25 & 0.09 & 0.16 & 0.2 & 0.06 \\
\hline \multirow[t]{2}{*}{ Kurtosis } & -1.4 & -1.37 & -1.42 & -1.7 & -1.47 & -1.74 & -1.8 \\
\hline & $\mathrm{CCN}$ & JLB & JLN & GSB & GSN & NMA & \\
\hline Mean & $10,824.90$ & $11,232.62$ & $10,177.87$ & $10,396.41$ & $11,737.13$ & $10,981.11$ & \\
\hline Stdev & 2655.17 & 2272.10 & 1860.66 & 2088.30 & 2758.61 & 2417.44 & \\
\hline Skewness & 0.16 & -0.3 & -0.23 & 0.23 & -0.12 & -0.02 & \\
\hline Kurtosis & -1.78 & -1.62 & -1.74 & -1.68 & -1.81 & -1.78 & \\
\hline
\end{tabular}

Note: The unit of the mean and standard deviation(Stdev) is ten thousand KRW. 


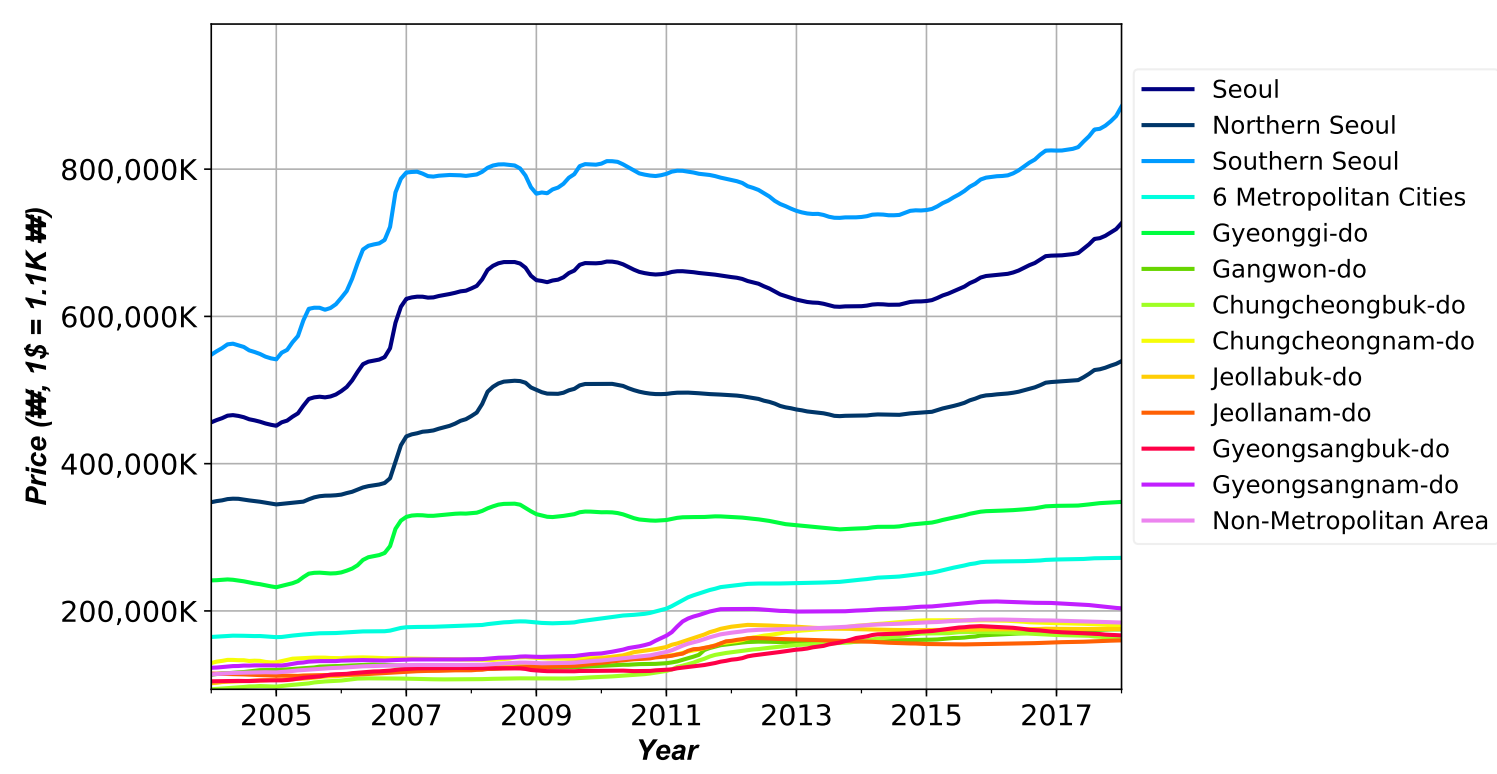

(a) House Price Index

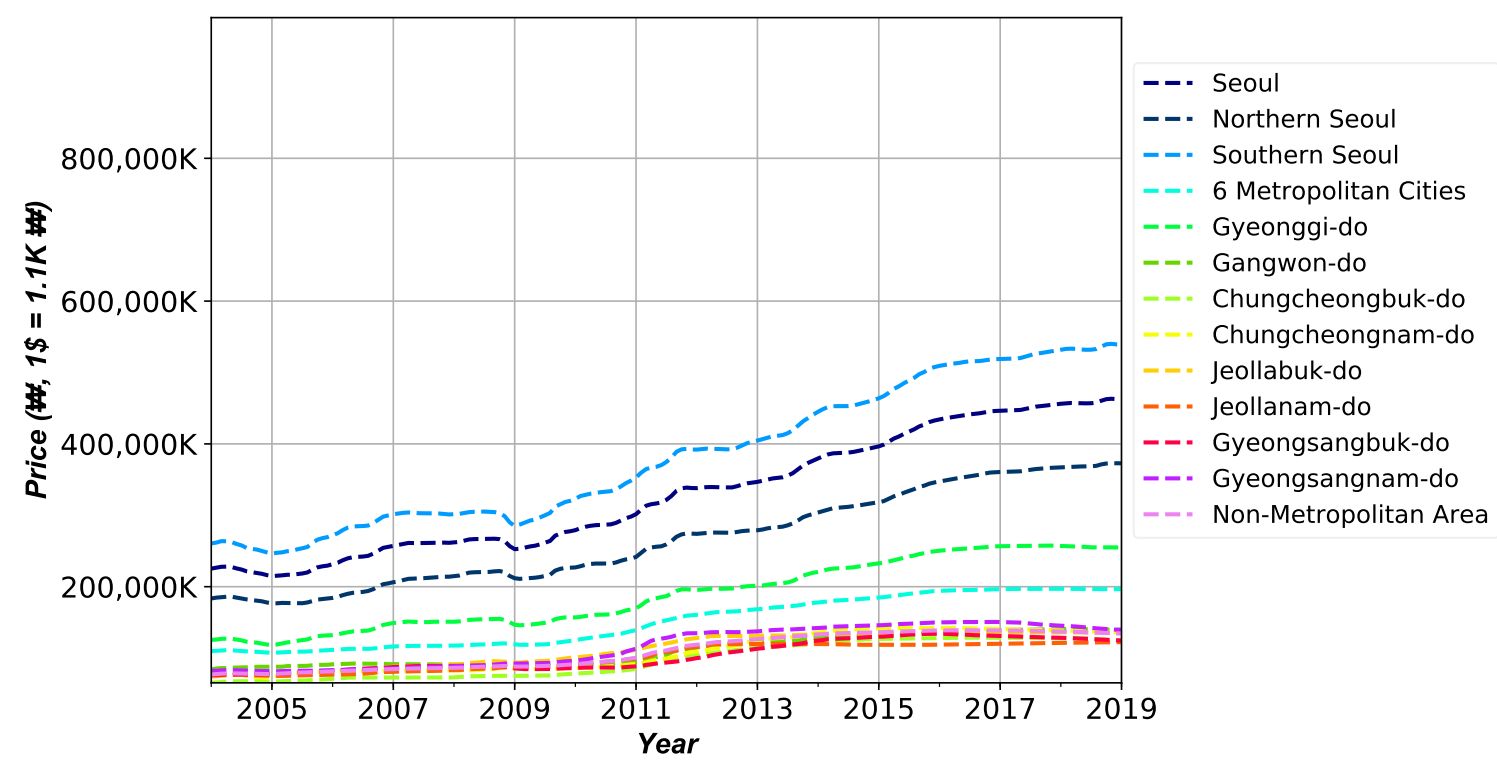

(b) Jeonse Deposit Index

Figure 3. Evolutions of HPI (Top) and JDI (Bottom) of the apartment in different regions.

According to the results of Tables 3 and 4, the overall statistics are similar to that of Table 2, with two interesting differences. At first, in the case of apartments, the JDI of SEL, NSEL, and SSEL is half of the corresponding HPI, but those of other regions are at least $60 \%$ to $80 \%$ of the HPI. Therefore, the different characteristics of bubbles in the real estate market are expected between the SEL regions and non-SEL regions. Secondly, the JDI of detached houses is about $40 \%$ of the HPI, whereas that of row houses is about $60 \%$ of the HPI. Hence, the characteristics of bubbles should be varied in different residential types. In terms of skewness and kurtosis, most regions show negative values with few positive exceptions. In summary, the price series of HPI and JDI show similar distributions. 
Table 4. Descriptive statistics for the detached and row houses' price series of HPI and JDI indices in different regions.

\begin{tabular}{|c|c|c|c|c|c|c|}
\hline \multicolumn{7}{|c|}{ (a) House Price Index (Detached) } \\
\hline & SEL & NSEL & SSEL & $6 \mathrm{MC}$ & GYG & NMA \\
\hline Mean & $68,115.46$ & $60,182.45$ & $80,711.96$ & $23,590.61$ & $44,836.42$ & $17,749.51$ \\
\hline Stdev & 8091.99 & 7185.91 & 9529.00 & 1879.73 & 2875.84 & 849.92 \\
\hline Skewness & -0.9 & -0.93 & -0.85 & 0.48 & -1.3 & 0.5 \\
\hline Kurtosis & -0.44 & -0.41 & -0.5 & -1.13 & 0.17 & -1.23 \\
\hline \multicolumn{7}{|c|}{ (b) Jeonse Deposit Index (Detached) } \\
\hline & SEL & NSEL & SSEL & $6 \mathrm{MC}$ & GYG & NMA \\
\hline Mean & $27,606.44$ & $24,732.88$ & $32,224.17$ & $10,222.93$ & $20,267.14$ & 8343.91 \\
\hline Stdev & 3868.53 & 3512.08 & 4426.08 & 915.20 & 1805.45 & 628 \\
\hline Skewness & -0.05 & -0.03 & -0.08 & 0.41 & -0.27 & 0.17 \\
\hline Kurtosis & -1.29 & -1.23 & -1.39 & -1.38 & -1.19 & -1.6 \\
\hline \multicolumn{7}{|c|}{ (c) House Price Index (Row) } \\
\hline & SEL & NSEL & SSEL & $6 \mathrm{MC}$ & GYG & NMA \\
\hline Mean & $24,657.47$ & $22,169.28$ & $27,240.82$ & $10,042.59$ & $14,462.48$ & 8127.94 \\
\hline Stdev & 2959.57 & 2725.39 & 3191.76 & 1314.74 & 2013.83 & 896.85 \\
\hline Skewness & -1.11 & -1.08 & -1.13 & -0.59 & -1.32 & 0.16 \\
\hline Kurtosis & -0.25 & -0.37 & -0.1 & -1.1 & 0.05 & -1.68 \\
\hline \multicolumn{7}{|c|}{ (d) Jeonse Deposit Index (Row) } \\
\hline & SEL & NSEL & SSEL & $6 \mathrm{MC}$ & GYG & NMA \\
\hline Mean & $14,650.19$ & $13,564.34$ & $15,788.89$ & 6654.70 & 8936.56 & 5643.83 \\
\hline Stdev & 2833.27 & 2653.73 & 3014.41 & 1007.61 & 1600.41 & 769.62 \\
\hline Skewness & 0.04 & 0.04 & 0.04 & -0.16 & -0.28 & 0.13 \\
\hline Kurtosis & -1.38 & -1.35 & -1.41 & -1.49 & -1.3 & -1.67 \\
\hline
\end{tabular}

Note: The unit of the mean and standard deviation(Stdev) is ten thousand KRW.

\subsubsection{Existence of Heteroscedasticity in Returns}

The return distributions of HPI and JDI, however, exhibit somewhat different patterns than the price distributions. Figure 4 demonstrates the evolutions of the return series of HPI and JDI, on average, for different residential types. Overall, the price fluctuations of HPI and JDI move in a similar direction with respect to time. The returns of the apartment are highly volatile from 2004 to 2012. Since then, the change has been declining. In particular, the dynamics of returns have become historically low during the last two years. The returns of detached and row houses show a similar pattern to that of an apartment with a different magnitude of volatility.

The descriptive statistics of the return series of HPI are summarized in Table 5. At first, the means and standard deviations of the return series show no significant difference from zero for all residential types. All return distributions are skewed right with fatter tails than the normal distribution, since their kurtoses are significantly greater than 3 . Such a phenomenon is supported by the results of the Kolmogorov-Smirnov and Jarque-Bera tests, whose statistics strongly reject the normality assumption at a $1 \%$ significance level. Besides, the $\mathrm{ARCH}$ test strongly rejects the assumption of no conditional heteroscedasticity for all residential types, which suggests the adequacy of a tree-based approach due to its incorporation of heteroscedasticity. The Ljung-Box (LB) test suggests that for an autocorrelation test of returns and squared returns, a high correlation is observed regardless of the size of lags. Lastly, the ADF test shows that most of the return series are non-stationary except that of a detached house at a $10 \%$ significance level. 
Furthermore, Tables 6 and 7 provide the descriptive statistics of the return series of HPI for different regions. The results show that all the return distributions are not normally distributed with autocorrelations in returns and squared returns. Although most of the return series are stationary, the existence of conditional heteroscedasticity is detected for all residential types and regions.

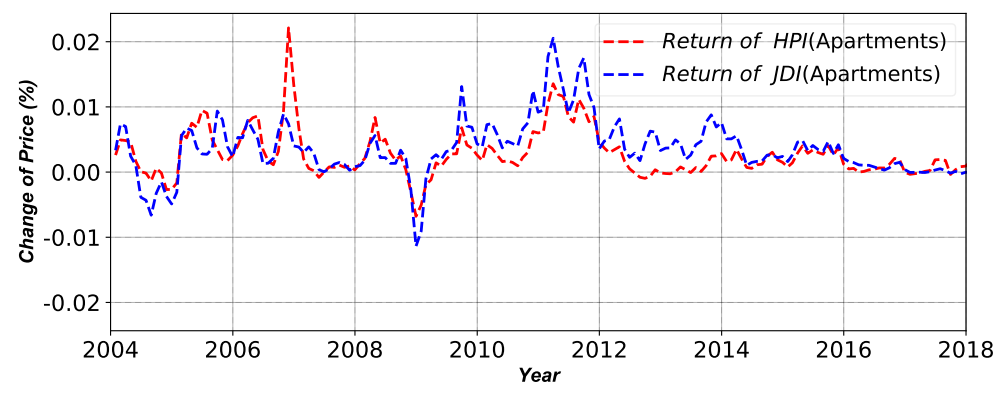

(a) Apartments

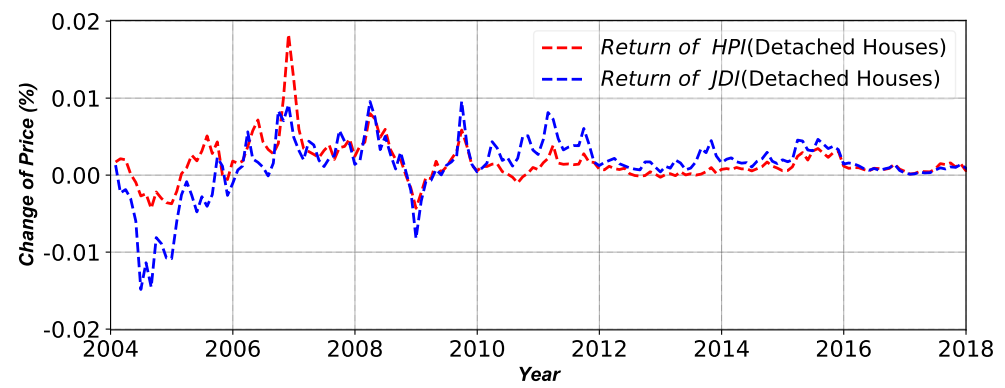

(b) Detached Houses

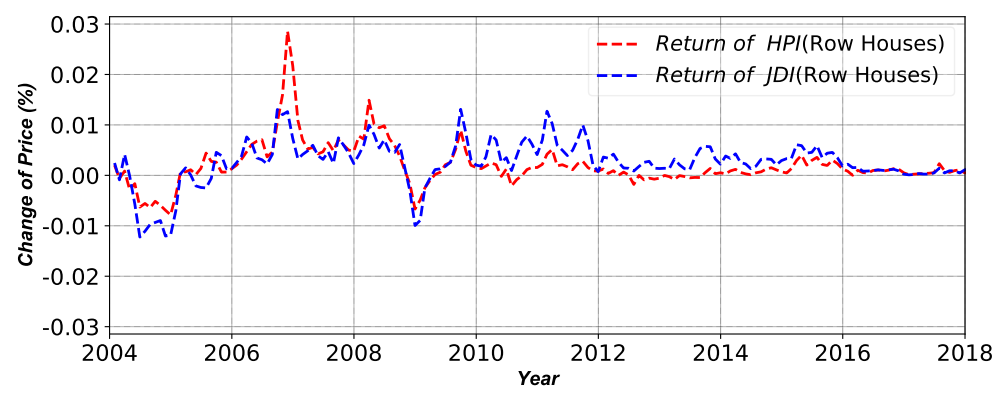

(c) Row Houses

Figure 4. Evolutions of the return series of aggregate HPI and JDI for different residential types.

Table 5. Descriptive statistics for the return series of HPI for different residential types.

\begin{tabular}{llll}
\hline & Apartments & Detached Houses & Row Houses \\
\hline Mean & 0.00 & 0.00 & 0.00 \\
Stdev & 0.01 & 0.00 & 0.00 \\
Skewness & 2.39 & 1.46 & 1.87 \\
Kurtosis & 11.69 & 9.78 & 9.76 \\
Kolmogorov-Smirnov & $0.50^{* * *}$ & $0.50^{* * *}$ & $0.50^{* * *}$ \\
Jarque-Bera & $2072.86^{* *}$ & $1094.00^{* * *}$ & $1325.70^{* * *}$ \\
ARCH(10) & $77.46^{* * *}$ & $61.76^{* * *}$ & $75.46^{* * *}$ \\
ARCH(20) & $78.26^{*}$ & $62.88^{* *}$ & $80.19^{* * *}$ \\
Ljung-Box(10) & $461.64^{* * *}$ & $295.00^{* * *}$ & $404.20^{* * *}$ \\
Ljung-Box(20) & $546.86^{* * *}$ & $373.87^{* * *}$ & $498.72^{* * *}$ \\
Ljung-Box(10) & $211.80^{* * *}$ & $87.24^{* * *}$ & $127.11^{* * *}$ \\
Ljung-Box(20) & $224.21^{* * *}$ & $109.90^{* * *}$ & $162.70^{* * *}$ \\
Augmented Dickey-Fuller & $-3.52^{* *}$ & $-3.80^{*}$ & -2.88 \\
\hline
\end{tabular}

Note: The star superscripts $* * *, * * *$ indicate the statistical significances at $10 \%, 5 \%, 1 \%$, respectively. 
Table 6. Descriptive statistics for the apartment's return series of HPI in different regions.

\begin{tabular}{|c|c|c|c|c|c|c|c|}
\hline & SEL & NSEL & SSEL & $6 \mathrm{MC}$ & GYG & GAW & ССВ \\
\hline Mean & 0.00 & 0.00 & 0.00 & 0.00 & 0.00 & 0.00 & 0.00 \\
\hline Stdev & 0.01 & 0.01 & 0.01 & 0.00 & 0.01 & 0.01 & 0.01 \\
\hline Skewness & 2.91 & 3.74 & 2.55 & 1.85 & 4.83 & 4.33 & 1.17 \\
\hline Kurtosis & 15.09 & 19.28 & 11.54 & 5.11 & 37.45 & 31.29 & 3.51 \\
\hline Kolmogorov-Smirnov & $0.49^{* * *}$ & $0.49^{* * *}$ & $0.49^{* * *}$ & $0.50 * * *$ & $0.49 * * *$ & $0.50^{* * *}$ & $0.49 * * *$ \\
\hline Jarque-Bera & $1858.11^{* * *}$ & $3040.15^{* * *}$ & $1130.76^{* * *}$ & $283.66^{* * *}$ & $10,614.09^{* * *}$ & $* 7484.37^{* * *}$ & $126.03^{* * *}$ \\
\hline ARCH(10) & $33.14^{* * *}$ & $76.58^{* * *}$ & $25.96^{* * *}$ & $139.32 * * *$ & $23.06^{* *}$ & $23.54^{* *}$ & $101.71^{* * *}$ \\
\hline $\mathrm{ARCH}(20)$ & $36.20 * *$ & $77.99^{* * *}$ & $33.33^{* *}$ & $133.81^{* * *}$ & 22.78 & 22.24 & $100.11^{* * *}$ \\
\hline Ljung-Box(10) & $177.43^{* * *}$ & $174.90 * * *$ & $178.45^{* * *}$ & $441.48^{* * *}$ & $169.44^{* * *}$ & $351.49^{* * *}$ & $709.02 * * *$ \\
\hline Ljung-Box(20) & $256.01^{* * *}$ & $276.57^{* * *}$ & $216.70 * * *$ & $445.90^{* * *}$ & $222.22 * * *$ & $354.80^{* * *}$ & $823.58^{* * *}$ \\
\hline Ljung-Box $(10)^{2}$ & $38.76^{* * *}$ & $68.58^{* * *}$ & $39.02 * * *$ & $377.43^{* * *}$ & $26.08^{* * *}$ & $42.79 * * *$ & $357.66^{* * *}$ \\
\hline 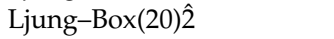 & $48.58^{* * *}$ & $87.76^{* * *}$ & $52.64 * * *$ & $378.79 * * *$ & 28.64 & $43.98 * * *$ & $362.17^{* * *}$ \\
\hline \multirow[t]{2}{*}{ Augmented Dickey-Fuller } & $-6.16^{* * *}$ & $-5.02^{* * *}$ & $-5.94^{* * *}$ & $-3.87^{* * *}$ & $-6.16^{* * *}$ & $-3.03^{* *}$ & -2.08 \\
\hline & $\mathrm{CCN}$ & JLB & JLN & GSB & GSN & NMA & \\
\hline Mean & 0.00 & 0.00 & 0.00 & 0.00 & 0.00 & 0.00 & \\
\hline Stdev & 0.00 & 0.00 & 0.00 & 0.00 & 0.01 & 0.00 & \\
\hline Skewness & 1.03 & 1.29 & 2.29 & 0.32 & 2.93 & 1.87 & \\
\hline Kurtosis & 1.27 & 1.33 & 8.62 & -0.03 & 12.45 & 5.02 & \\
\hline Kolmogorov-Smirnov & $0.50^{* * *}$ & $0.50 * * *$ & $0.50 * * *$ & $0.50 * * *$ & $0.50 * * *$ & $0.50^{* * *}$ & \\
\hline Jarque-Bera & $42.36^{* * *}$ & $60.65^{* * *}$ & $677.77^{* * *}$ & $3.09 * * *$ & $1346.49^{* * *}$ & $279.64^{* * *}$ & \\
\hline $\mathrm{ARCH}(10)$ & $86.35^{* * *}$ & $108.80^{* * *}$ & $63.50 * * *$ & $64.56^{* * *}$ & $121.51^{* * *}$ & $138.97^{* * *}$ & \\
\hline $\mathrm{ARCH}(20)$ & $94.91^{* * *}$ & $106.29 * * *$ & $72.37^{* * *}$ & $68.54^{* * *}$ & $115.81^{* * *}$ & $133.01^{* * *}$ & \\
\hline Ljung-Box(10) & $369.67^{* * *}$ & $710.27^{* * *}$ & $490.95^{* * *}$ & $759.76^{* * *}$ & $645.37^{* * *}$ & $823.12^{* * *}$ & \\
\hline Ljung-Box(20) & $536.01^{* * *}$ & $817.96^{* * *}$ & $545.31^{* * *}$ & $1018.44^{* * *}$ & $670.32^{* * *}$ & $925.33^{* * *}$ & \\
\hline Ljung-Box $(10)^{2}$ & $233.27 * * *$ & $458.37 * * *$ & $143.97 * * *$ & $210.02 * * *$ & $239.70^{* * *}$ & $517.77^{* * *}$ & \\
\hline 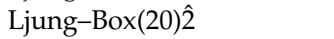 & $259.10 * * *$ & $499.45^{* * *}$ & $148.12^{* * *}$ & $239.62 * * *$ & $241.79^{* * *}$ & $524.05^{* * *}$ & \\
\hline Augmented Dickey-Fuller & -1.51 & $-2.70 *$ & $-2.87 *$ & -1.1 & $-3.00 * *$ & -2.27 & \\
\hline
\end{tabular}

Note: The star superscripts ${ }^{*}, * * * * *$ indicate the statistical significances at $10 \%, 5 \%, 1 \%$, respectively.

Table 7. Descriptive statistics for the detached and row houses' return series of HPI in different regions.

\begin{tabular}{|c|c|c|c|c|c|c|}
\hline \multicolumn{7}{|c|}{ (a) Detached Houses } \\
\hline & SEL & NSEL & SSEL & $6 \mathrm{MC}$ & GYG & NMA \\
\hline Mean & 0.00 & 0.00 & 0.00 & 0.00 & 0.00 & 0.00 \\
\hline Stdev & 0.00 & 0.00 & 0.00 & 0.00 & 0.00 & 0 \\
\hline Skewness & 2.55 & 2.04 & 3.41 & -0.91 & 2.65 & -1 \\
\hline Kurtosis & 11.35 & 6.58 & 19.22 & 2.86 & 15.5 & 3.16 \\
\hline Kolmogorov-Smirnov & $0.50^{* * *}$ & $0.50^{* * *}$ & $0.50 * * *$ & $0.50^{* * *}$ & $0.50^{* * *}$ & $0.50 * * *$ \\
\hline Jarque-Bera & $1099.36^{* * *}$ & $426.72^{* * *}$ & $2954.85^{* * *}$ & $80.62^{* * *}$ & $1903.93^{* * *}$ & $98.51^{* * *}$ \\
\hline $\mathrm{ARCH}(10)$ & $66.67^{* * *}$ & $76.11^{* * *}$ & $41.88^{* * *}$ & $72.43^{* * *}$ & $77.12^{* * *}$ & $36.32^{* * *}$ \\
\hline $\mathrm{ARCH}(20)$ & $70.25^{* * *}$ & $78.48^{* * *}$ & $43.00^{* * *}$ & $78.93^{* * *}$ & $76.87^{* * *}$ & $29.77^{* * *}$ \\
\hline Ljung-Box(10) & $323.31^{* * *}$ & $348.04^{* * *}$ & $186.55^{* * *}$ & $319.75^{* * *}$ & $234.75^{* * *}$ & $357.63^{* * *}$ \\
\hline Ljung-Box(20) & $464.16^{* * *}$ & $519.70^{* * *}$ & $237.31^{* * *}$ & $324.73^{* * *}$ & $263.71^{* * *}$ & $433.58^{* * *}$ \\
\hline Ljung-Box $(10)^{2}$ & $89.77^{* * *}$ & $117.73^{* * *}$ & $49.07^{* * *}$ & $137.36^{* * *}$ & $78.37^{* * *}$ & $51.17^{* * *}$ \\
\hline Ljung-Box(20)र̂2 & $123.22 * * *$ & $184.49^{* * *}$ & $57.38^{* * *}$ & $154.00^{* * *}$ & $85.25^{* * *}$ & $55.06^{* * *}$ \\
\hline Augmented Dickey-Fuller & -1.63 & $-3.94^{* * *}$ & $-5.63^{* * *}$ & $-3.69^{* * *}$ & $-3.85^{* * *}$ & $-4.07^{* * *}$ \\
\hline \multicolumn{7}{|c|}{ (b) Row Houses } \\
\hline & SEL & NSEL & SSEL & $6 \mathrm{MC}$ & GYG & NMA \\
\hline Mean & 0.00 & 0.00 & 0.00 & 0.00 & 0.00 & 0.00 \\
\hline Stdev & 0.01 & 0.01 & 0.01 & 0.00 & 0.01 & 0 \\
\hline Skewness & 2.17 & 2.08 & 2.18 & 0.85 & 4.34 & -0.37 \\
\hline Kurtosis & 9.03 & 6.77 & 10.02 & 2.91 & 27.26 & 2.58 \\
\hline Kolmogorov-Smirnov & $0.50 * * *$ & $0.50^{* * *}$ & $0.49^{* * *}$ & $0.50^{* * *}$ & $0.50^{* * *}$ & $0.50^{* * *}$ \\
\hline Jarque-Bera & $713.33^{* * *}$ & $449.61^{* * *}$ & $847.31^{* * *}$ & $79.81^{* * *}$ & $5814.00 * * *$ & $50.16^{* * *}$ \\
\hline $\mathrm{ARCH}(10)$ & $77.27^{* * *}$ & $88.36^{* * *}$ & $56.38^{* * *}$ & $87.96^{* * *}$ & $99.05^{* * *}$ & $43.72^{* * *}$ \\
\hline $\mathrm{ARCH}(20)$ & $80.16^{* * *}$ & $88.74^{* * *}$ & $59.98^{* * *}$ & $97.10^{* * *}$ & $94.23^{* * *}$ & $60.92^{* * * *}$ \\
\hline Ljung-Box(10) & $399.31^{* * *}$ & $468.75^{* * *}$ & $277.55^{* * *}$ & $507.24^{* * *}$ & $323.47^{* * *}$ & $448.88^{* * *}$ \\
\hline Ljung-Box(20) & $516.72^{* * *}$ & $618.33^{* * *}$ & $342.92 * * *$ & $554.53^{* * *}$ & $398.50^{* * *}$ & $561.31^{* * *}$ \\
\hline Ljung-Box $(10)^{2}$ & $118.07^{* * *}$ & $154.76^{* * *}$ & $83.33^{* * *}$ & $205.91^{* * *}$ & $92.63^{* * *}$ & $107.97^{* * *}$ \\
\hline Ljung-Box(20)र̂2 & $153.76^{* * *}$ & $221.63^{* * *}$ & $103.00^{* * *}$ & $292.87^{* * *}$ & $95.06^{* * *}$ & $109.86^{* * *}$ \\
\hline Augmented Dickey-Fuller & $-2.94 * *$ & -2.1 & -1.94 & $-3.44^{* *}$ & $-4.12^{* * *}$ & $-2.71 *$ \\
\hline
\end{tabular}

Note: The star superscripts ${ }^{*}, * * * * *$ indicate the statistical significances at $10 \%, 5 \%, 1 \%$, respectively. 
The heteroscedasticity can also be observed in the return distributions of JDI. In Figure 5, the returns of both HPI and JDI have similar distributions with fat tails. Interestingly, the clustering phenomenon can be detected in each of the large and small returns [83]. A high frequency in substantial returns can also be seen in the histograms for all residential types. The returns of apartments are the most widely distributed, and the returns of the detached and row houses tend to be narrowly distributed. Since heteroscedasticity is found in both HPI and JDI, we can assume the existence of heteroscedasticity in their spread, the difference between HPI and JDI. Therefore, we confirm that the different volatilities estimated by the GARCH model should be used for different residential types and regions.

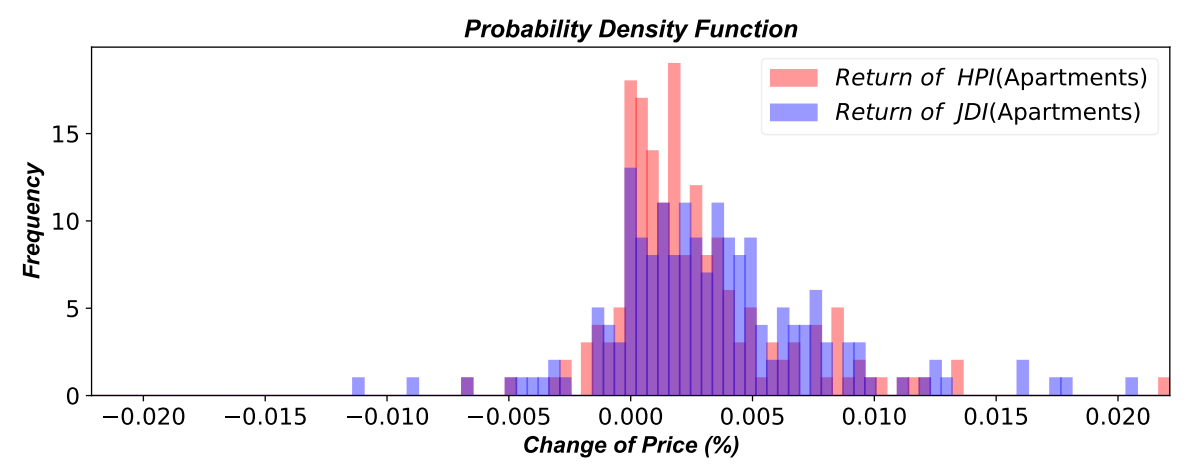

(a) Apartments

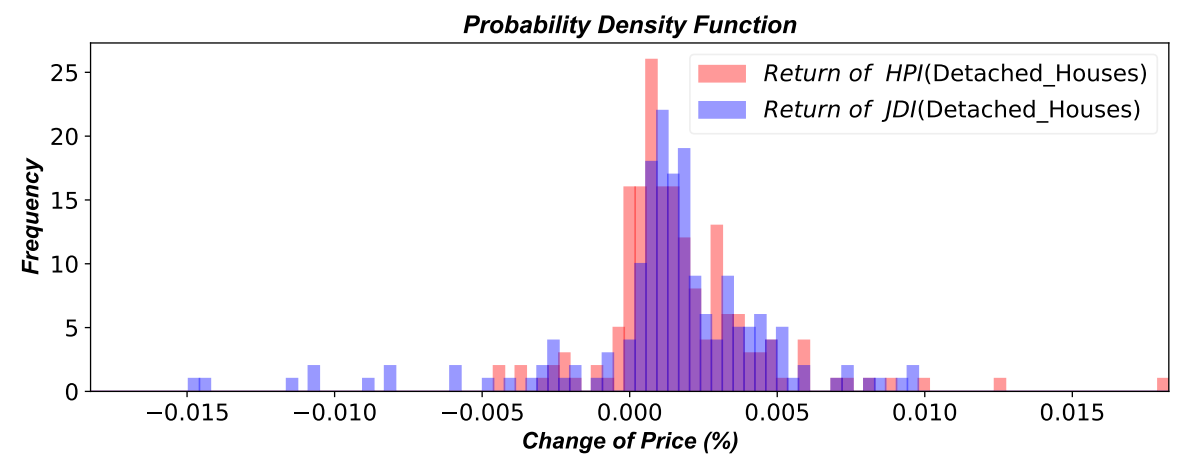

(b) Detached Houses

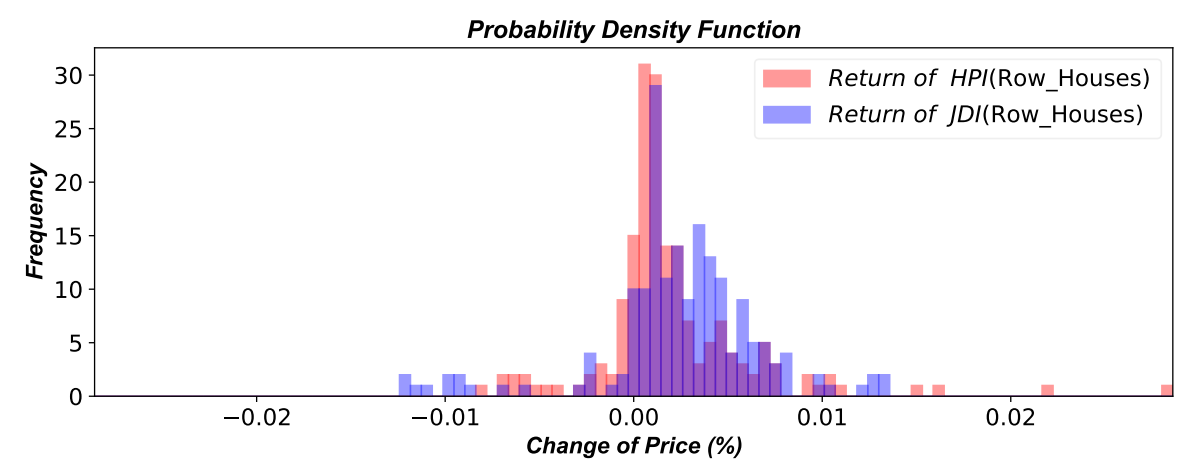

(c) Row Houses

Figure 5. The probability distribution of monthly returns of HPI and JDI for different residential types. 


\section{Results and Discussions}

\subsection{Analyses on Bubbles in Real Estate Market}

\subsubsection{Housing Bubbles in Total Period (2004-2018)}

In this paper, the spread, or the difference between HPI and JDI, has been analyzed for different types and regions by considering the characteristics of the Korean real estate market. Note that the spread can be considered as a bubble of a real estate since the JDI is the value of a residence. Such an approach can provide the opportunity for hedging the risk of each investment position, and present an appropriate investment strategy.

The bubbles in different residential types are summarized in Table 8. In the case of apartments, the maximum and minimum housing bubble was roughly 30 and -15 million KRW, respectively. In the case of detached houses, the average housing bubble is roughly four times higher than that of apartments. However, the maximum and minimum bubbles are smaller than those of apartments. The row house shows the smallest average annual housing bubble, being roughly 880K KRW among the three types of housing, with the lowest maximum and minimum bubbles. The percentage of an average annual housing bubble is $1.24 \%$ for a detached house, whereas it is $0.45 \%$ for both apartments and row houses. However, the differences in the percentages of the maximum and minimum bubbles for detached houses $(6 \%)$ is much smaller than those of apartments (12\%) and row houses (10\%). It is well-known that the apartments have the most transactions, whereas the detached houses have the least transactions. It implies that the small difference in the percentages of maximum and minimum bubbles in detached houses is from its low volumes of transactions.

Table 8. Overall housing bubbles for different residential types.

\begin{tabular}{lllllll}
\hline & Average & Average (\%) & Max & Max (\%) & Min & Min (\%) \\
\hline Apartments & 208.56 & $0.45 \%$ & 3014.33 & $7.97 \%$ & -1539.26 & $-4.32 \%$ \\
Detached & 746.91 & $1.24 \%$ & 2577.54 & $4.53 \%$ & -625.21 & $-1.17 \%$ \\
Row & 87.72 & $0.45 \%$ & 1226.99 & $6.37 \%$ & -633.74 & $-3.29 \%$ \\
\hline
\end{tabular}

Note: The unit of the average, max, and min is ten thousand KRW. Also, (\%) indicates the percent of each value for average house price.

Similar to Table 8, Table 9 summarizes the housing bubbles in different residential types for different regions. In the case of the apartment, the top three annual housing bubbles in proportion to house prices are regions in Seoul with SSEL (1.48\%) > SEL (0.95\%) > NSEL (1.28\%), which reflects the aspects of the most populated city in Korea. Given that other regions exhibit the bubbles between $-0.5 \%$ and $0.67 \%$, it is clear that the regions in SEL show relatively large bubbles. The top three of the maximum housing bubble are also SSEL (16.18\%) > SEL (14.87\%) > NSEL (13.27\%), followed by GSN $(12.76 \%)$, which has higher economic development than other regions, and GYG $(11.80 \%)$, which has the highest population density after Seoul. On the other hand, the minimum housing bubble is GYG $(-8 \%)$, followed by NSEL $(-7.53 \%)>$ SEL $(-7.21 \%)>$ SSEL $(-7.05 \%)$. As the regions in SEL possess the highest population density, the expectations on the increase in house prices are higher than those of other regions, which eventually leads to larger bubbles. However, if the absolute size of the bubble is only dependent on trade volume or population density regardless of location, then both the maximum and minimum housing bubbles should be SSEL, which it is not. It implies that the size of the bubble is also dependent on regional characteristics, such as average income, economic development, and plans on social overhead capital.

The bubbles in the detached houses can be divided into six regions, as listed in Table 9b. Similar to the apartments, the average annual housing bubble in proportion to house price is roughly $2 \%$ in SEL, whereas those of other regions are less than $1 \%$. While the maximum housing bubbles of SEL and GYG are over $5 \%$, that of $6 \mathrm{MC}$ and other regions are roughly $3 \%$ and $1 \%$, respectively. However, the size of the minimum housing bubbles is similar in all regions by $-1 \%$. It implies that the housing bubbles 
do not move symmetrically between positive (maximum) and negative (minimum) bubbles, and the negative bubbles seem more irrelevant to the regions than the apartment.

Lastly, the bubbles in the row houses show a different pattern in comparison to those of apartments and detached houses. All regions except NMA show a similar size of bubbles in every aspect. It implies that the people living in row houses have a lower preference in residential regions than those living in other residential types.

Table 9. Bubbles for different residential types and regions.

\begin{tabular}{lllllll}
\hline \multicolumn{7}{c}{ (a) Apartments } \\
\hline Average & Average (\%) & Max & Max(\%) & Min & Min (\%) \\
\hline NSEL & 803.85 & $1.28 \%$ & 9315.66 & $14.87 \%$ & -4515.16 & $-7.21 \%$ \\
SSEL & 112.6 & $0.95 \%$ & 6202.18 & $13.27 \%$ & -3521.08 & $-7.53 \%$ \\
6MC & 146.36 & $1.48 \%$ & $12,299.4$ & $16.18 \%$ & -5357.81 & $-7.05 \%$ \\
GYG & -58.6 & $-0.67 \%$ & 1137.7 & $5.23 \%$ & -539.57 & $-2.48 \%$ \\
GAW & 27.14 & $0.19 \%$ & 3720.88 & $11.80 \%$ & -2523.05 & $-8.00 \%$ \\
CCB & 24.26 & $0.18 \%$ & 459.59 & $3.19 \%$ & -644.28 & $-4.47 \%$ \\
CCN & -77.6 & $-0.50 \%$ & 595.64 & $4.45 \%$ & -461.98 & $-3.45 \%$ \\
JLB & 68.62 & $0.46 \%$ & 1057.9 & $7.81 \%$ & -379.51 & $-2.42 \%$ \\
JLN & 11.17 & $0.08 \%$ & 272.97 & $1.95 \%$ & -539.14 & $-3.61 \%$ \\
GSB & 52.37 & $0.38 \%$ & 484.55 & $3.48 \%$ & -375.27 & $-1.98 \%$ \\
GSN & 91.97 & $0.54 \%$ & 2184.61 & $12.76 \%$ & -598.28 & $-2.70 \%$ \\
NMA & 53.37 & $0.35 \%$ & 858.69 & $5.56 \%$ & -278.9 & $-1.81 \%$ \\
\hline
\end{tabular}

(b) Detached Houses

\begin{tabular}{lllllll}
\hline & Average & Average (\%) & Max & Max(\%) & Min & Min (\%) \\
\hline SEL & 1264.2 & $1.86 \%$ & 3829.81 & $5.62 \%$ & -961.64 & $-1.41 \%$ \\
NSEL & 1093.86 & $1.82 \%$ & 3613.74 & $6.00 \%$ & -1102.01 & $-1.83 \%$ \\
SSEL & 1544.08 & $1.91 \%$ & 4708.97 & $5.83 \%$ & -854.88 & $-1.06 \%$ \\
6MC & 228.91 & $0.97 \%$ & 740.99 & $3.14 \%$ & -74.26 & $-0.31 \%$ \\
GYG & 325.17 & $0.73 \%$ & 2326.3 & $5.19 \%$ & -556.47 & $-1.24 \%$ \\
NMA & 25.25 & $0.14 \%$ & 245.43 & $1.38 \%$ & -201.99 & $-1.14 \%$ \\
\hline
\end{tabular}

(c) Row Houses

\begin{tabular}{lllllll}
\hline & Average & Average (\%) & Max & Max(\%) & Min & Min (\%) \\
\hline SEL & 124.63 & $0.51 \%$ & 1808.22 & $7.33 \%$ & -939.09 & $-3.81 \%$ \\
NSEL & 92.02 & $0.42 \%$ & 1759.58 & $7.94 \%$ & -862.45 & $-3.89 \%$ \\
SSEL & 160.92 & $0.59 \%$ & 1816.61 & $6.67 \%$ & -1015.19 & $-3.73 \%$ \\
6MC & 61.72 & $0.61 \%$ & 564.24 & $5.62 \%$ & -153.22 & $-1.53 \%$ \\
GYG & 94.08 & $0.65 \%$ & 1253.43 & $8.67 \%$ & -643.53 & $-4.45 \%$ \\
NMA & -7.05 & $-0.09 \%$ & 159.85 & $1.97 \%$ & -188.95 & $-2.32 \%$ \\
\hline
\end{tabular}

Note: The unit of the average, max, and $\min$ is ten thousand KRW.

\subsubsection{Housing Bubbles in Different Cross-Sections}

Although the characteristics of housing bubbles by residential types and regions have been summarized, it is difficult to track changes in housing bubbles over different time horizons. Therefore, the cross-sectional housing bubbles for three periods are shown in Tables 10-12 by dividing the period of 15 years into five-year units. At first, the average housing bubbles during 2004-2008, 2009-2013, and 2014-2018 in Table 10 are ranged from 7 to 18 million KRW, from -9 to -2 million KRW, and from 0.15 to 6 million KRW, respectively. The result suggests a different range of bubbles with respect to time. In particular, it is noteworthy that 2009-2013 includes the sub-prime mortgage crisis.

More detailed results on cross-sectional bubbles for different residential types and regions can be found in Tables 11 and 12. In the case of apartments summarized in Table 11, the average housing bubbles in proportion to house price in the total period are roughly between $-0.5 \%$ to $1.5 \%$. 
However, the average housing bubbles during 2004-2008, 2009-2013, and 2014-2018 are much more widely ranged from $-0.28 \%$ to $5.57 \%$, from $-6.20 \%$ to $1.55 \%$, and from $-0.64 \%$ to $4.37 \%$, respectively. The maximum and minimum bubbles also exhibit different trends in different cross-sections. Also, similar results can be found in detached and row houses, as summarized in Table 12.

The spread-based housing bubble presented in this study is not merely represented by a single value, but seems to capture trends well over time. Therefore, real estate traders can integrate the housing bubbles and corresponding trading strategy based on arbitrage elimination in their decision-making.

Table 10. Cross-sectional overall bubbles for different residential types.

\begin{tabular}{lllllll}
\hline 2004-2008 & Average & Average (\%) & Max & Max (\%) & Min & Min (\%) \\
\hline Apartments & 966.199 & $2.03 \%$ & 2292.99 & $5.16 \%$ & 70.0989 & $-0.38 \%$ \\
Detached & 1805.48 & $2.77 \%$ & 2474.64 & $4.03 \%$ & 1170.18 & $1.65 \%$ \\
Row & 661.467 & $3.07 \%$ & 1203.2 & $6.07 \%$ & 46.7639 & $-0.18 \%$ \\
\hline 2009-2013 & Average & Average (\%) & Max & Max (\%) & Min & Min (\%) \\
\hline Apartments & -900.633 & $-1.55 \%$ & 22.1706 & $2.32 \%$ & -1496.71 & $-4.03 \%$ \\
Detached & -164.865 & $-0.25 \%$ & 468.274 & $0.94 \%$ & -607.426 & $-1.07 \%$ \\
Row & -413.614 & $-1.85 \%$ & -74.7822 & $0.04 \%$ & -611.026 & $-3.01 \%$ \\
\hline 2014-2018 & Average & Average (\%) & Max & Max (\%) & Min & Min (\%) \\
\hline Apartments & 560.112 & $0.88 \%$ & 2477.1 & $5.19 \%$ & -442.214 & $-1.69 \%$ \\
Detached & 600.112 & $1.19 \%$ & 2059.37 & $3.60 \%$ & -149.03 & $-0.15 \%$ \\
Row & 15.3128 & $0.12 \%$ & 490.592 & $2.29 \%$ & -328.929 & $-1.56 \%$ \\
\hline
\end{tabular}

Note: The unit of the average, max, and min is ten thousand KRW.

Table 11. Cross-sectional bubbles of apartments in different regions.

\begin{tabular}{lllllll}
\hline 2004-2008 & Average & Average (\%) & Max & Max (\%) & Min & Min (\%) \\
\hline SEL & 3490.69 & $5.57 \%$ & 6656.87 & $10.63 \%$ & 825.135 & $1.32 \%$ \\
NSEL & 2596.97 & $5.56 \%$ & 5079.85 & $10.87 \%$ & 197.541 & $0.42 \%$ \\
SSEL & 4174.76 & $5.49 \%$ & 11389.2 & $14.98 \%$ & 1052.68 & $1.38 \%$ \\
6MC & 219.375 & $1.01 \%$ & 397.613 & $1.83 \%$ & 30.1186 & $0.14 \%$ \\
GYG & 1492.28 & $4.73 \%$ & 3720.88 & $11.80 \%$ & 70.8455 & $0.22 \%$ \\
GAW & 85.689 & $0.59 \%$ & 252.08 & $1.75 \%$ & -262.664 & $-1.82 \%$ \\
CCB & 96.376 & $0.72 \%$ & 269.287 & $2.01 \%$ & -132.751 & $-0.99 \%$ \\
CCN & -14.4131 & $-0.09 \%$ & 596.522 & $3.81 \%$ & -360.987 & $-2.30 \%$ \\
JLB & 130.412 & $0.87 \%$ & 494.859 & $3.31 \%$ & -68.9238 & $-0.46 \%$ \\
JLN & -39.5559 & $-0.28 \%$ & 63.7614 & $0.46 \%$ & -142.732 & $-1.02 \%$ \\
GSB & 138.627 & $1.00 \%$ & 271.922 & $1.95 \%$ & 3.48114 & $0.03 \%$ \\
GSN & 100.376 & $0.59 \%$ & 398.847 & $2.33 \%$ & -196.426 & $-1.15 \%$ \\
NMA & 89.0019 & $0.58 \%$ & 217.181 & $1.41 \%$ & -104.027 & $-0.67 \%$ \\
\hline 2009-2013 & Average & Average $\%$ (\%) & Max & Max $\mathbf{( \% )}$ & Min & Min $\mathbf{( \% )}$ \\
\hline SEL & -3413.25 & $-5.45 \%$ & -1787.6 & $-2.85 \%$ & -4515.16 & $-7.21 \%$ \\
NSEL & -2596.9 & $-5.56 \%$ & -1457.47 & $-3.12 \%$ & -3521.08 & $-7.53 \%$ \\
SSEL & -4127.96 & $-5.43 \%$ & -2024.14 & $-2.66 \%$ & -5357.81 & $-7.05 \%$ \\
6MC & -41.5118 & $-0.19 \%$ & 1137.7 & $5.23 \%$ & -539.57 & $-2.48 \%$ \\
GYG & -1955.45 & $-6.20 \%$ & -1433.41 & $-4.54 \%$ & -2523.05 & $-8.00 \%$ \\
GAW & -84.3868 & $-0.59 \%$ & 459.592 & $3.19 \%$ & -644.284 & $-4.47 \%$ \\
CCB & 62.1106 & $0.46 \%$ & 595.639 & $4.45 \%$ & -191.469 & $-1.43 \%$ \\
CCN & -161.004 & $-1.03 \%$ & -19.7842 & $-0.13 \%$ & -379.51 & $-2.42 \%$ \\
JLB & 155.607 & $1.04 \%$ & 1057.9 & $7.08 \%$ & -539.138 & $-3.61 \%$ \\
JLN & 51.9528 & $0.37 \%$ & 272.965 & $1.95 \%$ & -276.265 & $-1.98 \%$ \\
GSB & 35.5882 & $0.26 \%$ & 443.519 & $3.19 \%$ & -255.715 & $-1.84 \%$ \\
GSN & 266.236 & $1.55 \%$ & 2184.61 & $12.76 \%$ & -452.8 & $-2.64 \%$ \\
\hline
\end{tabular}


Table 11. Cont.

\begin{tabular}{lllllll}
\hline 2014-2018 & Average & Average (\%) & Max & Max (\%) & Min & Min (\%) \\
\hline SEL & 2334.1 & $3.73 \%$ & 9315.66 & $14.87 \%$ & -1016.02 & $-1.62 \%$ \\
NSEL & 1336.73 & $2.86 \%$ & 6202.18 & $13.27 \%$ & -1036.53 & $-2.22 \%$ \\
SSEL & 3321.46 & $4.37 \%$ & $12,299.4$ & $16.18 \%$ & -924.262 & $-1.22 \%$ \\
6MC & 261.228 & $1.20 \%$ & 684.205 & $3.15 \%$ & 94.8125 & $0.44 \%$ \\
GYG & 287.38 & $0.91 \%$ & 1495.58 & $4.74 \%$ & -531.157 & $-1.68 \%$ \\
GAW & 80.1222 & $0.56 \%$ & 246.425 & $1.71 \%$ & -41.376 & $-0.29 \%$ \\
CCB & -85.7081 & $-0.64 \%$ & 592.651 & $4.43 \%$ & -461.981 & $-3.45 \%$ \\
CCN & -57.3888 & $-0.37 \%$ & 192.809 & $1.23 \%$ & -212.824 & $-1.36 \%$ \\
JLB & -80.1508 & $-0.54 \%$ & 22.8853 & $0.15 \%$ & -172.382 & $-1.15 \%$ \\
JLN & 21.1013 & $0.15 \%$ & 197.939 & $1.42 \%$ & -194.572 & $-1.39 \%$ \\
GSB & -17.1028 & $-0.12 \%$ & 484.548 & $3.48 \%$ & -375.309 & $-2.70 \%$ \\
GSN & -90.6892 & $-0.53 \%$ & 301.119 & $1.76 \%$ & -598.275 & $-3.49 \%$ \\
NMA & -29.6301 & $-0.19 \%$ & 166.876 & $1.08 \%$ & -278.902 & $-1.81 \%$ \\
\hline
\end{tabular}

Note: The unit of the average, max, and min is ten thousand KRW.

Table 12. Cross-sectional bubbles of detached and row houses in different regions.

\begin{tabular}{|c|c|c|c|c|c|c|}
\hline \multicolumn{7}{|c|}{ (a) Detached Houses } \\
\hline 2004-2008 & Average & Average (\%) & $\operatorname{Max}$ & $\operatorname{Max}(\%)$ & Min & $\operatorname{Min}(\%)$ \\
\hline SEL & 3099.05 & $4.55 \%$ & 3829.81 & $5.62 \%$ & 2268.57 & $3.33 \%$ \\
\hline NSEL & 2722.93 & $4.52 \%$ & 3613.74 & $6.00 \%$ & 2149.3 & $3.57 \%$ \\
\hline SSEL & 3706 & $4.59 \%$ & 4708.97 & $5.83 \%$ & 2254.8 & $2.79 \%$ \\
\hline $6 \mathrm{MC}$ & 221.606 & $0.94 \%$ & 392.124 & $1.66 \%$ & 53.8378 & $0.23 \%$ \\
\hline GYG & 1194.74 & $2.66 \%$ & 2326.3 & $5.19 \%$ & 496.533 & $1.11 \%$ \\
\hline NMA & -111.423 & $-0.63 \%$ & -23.0936 & $-0.13 \%$ & -201.994 & $-1.14 \%$ \\
\hline 2009-2013 & Average & Average (\%) & $\operatorname{Max}$ & $\operatorname{Max}(\%)$ & Min & $\operatorname{Min}(\%)$ \\
\hline SEL & -242.229 & $-0.36 \%$ & 886.243 & $1.30 \%$ & -961.641 & $-1.41 \%$ \\
\hline NSEL & -261.757 & $-0.43 \%$ & 1033.7 & $1.72 \%$ & -1102.01 & $-1.83 \%$ \\
\hline SSEL & -186.526 & $-0.23 \%$ & 512.657 & $0.64 \%$ & -854.88 & $-1.06 \%$ \\
\hline $6 \mathrm{MC}$ & 84.2543 & $0.36 \%$ & 239.023 & $1.01 \%$ & -74.2565 & $-0.31 \%$ \\
\hline GYG & -391.243 & $-0.87 \%$ & -52.9516 & $-0.12 \%$ & -556.472 & $-1.24 \%$ \\
\hline NMA & 8.31277 & $0.05 \%$ & 190.974 & $1.08 \%$ & -95.2954 & $-0.54 \%$ \\
\hline 2014-2018 & Average & Average (\%) & $\operatorname{Max}$ & $\operatorname{Max}(\%)$ & Min & $\operatorname{Min}(\%)$ \\
\hline SEL & 935.79 & $1.37 \%$ & 3537.22 & $5.19 \%$ & -319.168 & $-0.47 \%$ \\
\hline NSEL & 820.408 & $1.36 \%$ & 3329.27 & $5.53 \%$ & -424.143 & $-0.70 \%$ \\
\hline SSEL & 1112.76 & $1.38 \%$ & 3744.77 & $4.64 \%$ & -83.0129 & $-0.10 \%$ \\
\hline $6 \mathrm{MC}$ & 380.861 & $1.61 \%$ & 740.99 & $3.14 \%$ & 135.738 & $0.58 \%$ \\
\hline GYG & 171.996 & $0.38 \%$ & 758.525 & $1.69 \%$ & -276.271 & $-0.62 \%$ \\
\hline NMA & 178.856 & $1.01 \%$ & 245.427 & $1.38 \%$ & 72.6751 & $0.41 \%$ \\
\hline \multicolumn{7}{|c|}{ (b) Row Houses } \\
\hline 2004-2008 & Average & Average (\%) & Max & $\operatorname{Max}(\%)$ & Min & $\operatorname{Min}(\%)$ \\
\hline SEL & 1062.24 & $4.31 \%$ & 1808.22 & $7.33 \%$ & 194.482 & $0.79 \%$ \\
\hline NSEL & 934.474 & $4.22 \%$ & 1759.58 & $7.94 \%$ & 239.479 & $1.08 \%$ \\
\hline SSEL & 1198.04 & $4.40 \%$ & 1816.61 & $6.67 \%$ & 139.711 & $0.51 \%$ \\
\hline $6 \mathrm{MC}$ & 216.806 & $2.16 \%$ & 564.236 & $5.62 \%$ & -132.008 & $-1.31 \%$ \\
\hline GYG & 651.102 & $4.50 \%$ & 1253.43 & $8.67 \%$ & 27.8679 & $0.19 \%$ \\
\hline NMA & -93.8577 & $-1.15 \%$ & 17.1061 & $0.21 \%$ & -188.948 & $-2.32 \%$ \\
\hline
\end{tabular}


Table 12. Cont.

\begin{tabular}{lllllll}
\hline 2009-2013 & Average & Average (\%) & Max & Max (\%) & Min & Min (\%) \\
\hline SEL & -699.892 & $-2.84 \%$ & -225.737 & $-0.92 \%$ & -939.092 & $-3.81 \%$ \\
NSEL & -629.412 & $-2.84 \%$ & -24.0378 & $-0.11 \%$ & -862.445 & $-3.89 \%$ \\
SSEL & -773.652 & $-2.84 \%$ & -473.345 & $-1.74 \%$ & -1015.19 & $-3.73 \%$ \\
6MC & -65.7654 & $-0.65 \%$ & 76.7329 & $0.76 \%$ & -153.222 & $-1.53 \%$ \\
GYG & -361.944 & $-2.50 \%$ & 37.8466 & $0.26 \%$ & -643.533 & $-4.45 \%$ \\
NMA & 48.9828 & $0.60 \%$ & 159.847 & $1.97 \%$ & -52.6737 & $-0.65 \%$ \\
\hline 2014-2018 & Average & Average (\%) & Max & Max (\%) & Min & Min (\%) \\
\hline SEL & 11.5463 & $0.05 \%$ & 825.046 & $3.35 \%$ & -555.859 & $-2.25 \%$ \\
NSEL & -29.0032 & $-0.13 \%$ & 675.531 & $3.05 \%$ & -562.471 & $-2.54 \%$ \\
SSEL & 58.3815 & $0.21 \%$ & 994.987 & $3.65 \%$ & -542.791 & $-1.99 \%$ \\
6MC & 34.1288 & $0.34 \%$ & 78.1045 & $0.78 \%$ & -29.917 & $-0.30 \%$ \\
GYG & -6.91171 & $-0.05 \%$ & 299.747 & $2.07 \%$ & -218.741 & $-1.51 \%$ \\
NMA & 23.735 & $0.29 \%$ & 70.1392 & $0.86 \%$ & -63.7951 & $-0.78 \%$ \\
\hline
\end{tabular}

Note: The unit of the average, max, and min is ten thousand KRW.

\subsection{Reduction of Housing Bubbles for Sustainable Real Estate Market}

\subsubsection{Effectiveness of Early Exercise}

The Contract period for the Jeonse system is usually two years ( 24 months) for apartments and one year (12 months) for other residential types. Note that the one-year Contract is also available for the apartment. Although the relatively long Contract period is part of a policy to reduce the tenant's instability in residence, such a policy also restricts active transactions in the real estate market. Besides, a tenant may terminate the Contract earlier than the agreed term if another candidate is wishing to reside in the property where they currently live. However, early termination of the Contract is not ordinary due to removal expenses, the real estate agent's commission, and, more importantly, lack of information regarding the present value of the current residence. Therefore, we believe that early elimination could be promoted based on the estimated residential values provided to market participants.

From the modeling perspective, the difference between the European and the American option is the allowance of early exercise. In particular, the two options have the same price at the expiration date, but the American option is more valuable than the European one before the expiration date due to the possibility of early exercise. Note that the real estate Contract in Korea can be modeled as an American option if a tenant decides to terminate the Contract early.

In this circumstance, the main phenomena that we aimed to analyze are twofold. Firstly, by applying the European and American options simultaneously based on bubbles and the spread defined by the difference between the HPI and JDI, we investigated the arbitrage opportunities that maximize traders' position values when early exercise is possible. Secondly, by assuming early exercise is well-executed with information on the arbitrage opportunity, we measured the size of the reduction of housing bubbles for each opportunity.

Table 13 summarizes the size of the housing bubble in the percentage of the corresponding house price for cases of the European option with no early exercise, and the American option with early exercise in different residential types and regions. Note that a single value in the table represents the average of bubbles from the last 15 years. In the case of the apartment for all regions, the reduction of the average bubble from the early exercise is roughly $33 \%(0.45 \% \rightarrow 0.3 \%)$. Although the maximum value of the housing bubbles decreased and the minimum value increased, the average value of the housing bubbles decreased significantly due to early events. In the case of detached houses for all regions, the housing bubbles reduced for all cases of average $(1.24 \% \rightarrow 1.17 \%)$, maximum $(4.53 \% \rightarrow 4.52 \%)$, and minimum $(-1.17 \% \rightarrow-1.16 \%)$ values. Along with the results of the apartments and detached houses ((a) All, Table 13), the row houses also exhibited the largest $40 \%$ reduction of bubbles on average $(0.45 \% \rightarrow 0.27 \%)$. 
Table 13. Comparisons for the bubbles between with and without early exercise.

\begin{tabular}{|c|c|c|c|c|c|c|c|c|c|}
\hline \multicolumn{10}{|c|}{ (a) All } \\
\hline & Average (NoEarly) & Left $>$ Right & Average (Early) & Max (NoEarly) & Left $>$ Right & Max (Early) & Min (NoEarly) & Left $>$ Right & Min (Early) \\
\hline Apartments & 0.45 & TRUE & 0.3 & 7.97 & TRUE & 7.68 & -4.32 & FALSE & -4.42 \\
\hline Detached & 1.24 & TRUE & 1.17 & 4.53 & TRUE & 4.52 & -1.17 & TRUE & -1.16 \\
\hline Row & 0.45 & TRUE & 0.27 & 6.37 & TRUE & 6.32 & -3.29 & FALSE & -3.3 \\
\hline \multicolumn{10}{|c|}{ (b) Apartments } \\
\hline & Average (NoEarly) & Left $>$ Right & Average (Early) & Max (NoEarly) & Left $>$ Right & Max (Early) & Min (NoEarly) & Left $>$ Right & Min (Early) \\
\hline SEL & 1.28 & TRUE & 1.19 & 14.87 & TRUE & 14.87 & -7.21 & TRUE & -7.21 \\
\hline NSEL & 0.95 & TRUE & 0.75 & 13.27 & TRUE & 13.27 & -7.53 & TRUE & -7.53 \\
\hline SSEL & 1.48 & TRUE & 1.45 & 16.18 & TRUE & 16.18 & -7.05 & TRUE & -7.05 \\
\hline $6 \mathrm{MC}$ & 0.67 & TRUE & 0.53 & 5.23 & TRUE & 4.79 & -2.48 & FALSE & -2.66 \\
\hline GYG & -0.19 & FALSE & -0.4 & 11.8 & TRUE & 11.45 & -8 & TRUE & -8 \\
\hline GAW & 0.19 & TRUE & -0.08 & 3.19 & TRUE & 1.71 & -4.47 & TRUE & -4.47 \\
\hline ССВ & 0.18 & TRUE & 0 & 4.45 & TRUE & 4.43 & -3.45 & TRUE & -3.45 \\
\hline $\mathrm{CCN}$ & -0.5 & FALSE & -0.76 & 3.81 & TRUE & 2.63 & -2.42 & FALSE & -3.5 \\
\hline JLB & 0.46 & TRUE & 0.36 & 7.08 & TRUE & 6.51 & -3.61 & TRUE & -3.61 \\
\hline JLN & 0.08 & TRUE & -0.06 & 1.95 & FALSE & 2.66 & -1.98 & TRUE & -1.98 \\
\hline GSB & 0.38 & TRUE & 0.2 & 3.48 & TRUE & 3.48 & -2.7 & TRUE & -2.7 \\
\hline GSN & 0.54 & TRUE & 0.41 & 12.76 & TRUE & 12.76 & -3.49 & TRUE & -3.49 \\
\hline NMA & 0.35 & TRUE & 0.25 & 5.56 & TRUE & 5.11 & -1.81 & TRUE & -1.81 \\
\hline \multicolumn{10}{|c|}{ (c) Detached Houses } \\
\hline & Average (NoEarly) & Left $>$ Right & Average (Early) & Max (NoEarly) & Left $>$ Right & Max (Early) & Min (NoEarly) & Left $>$ Right & Min (Early) \\
\hline SEL & 1.86 & TRUE & 1.77 & 5.62 & TRUE & 5.62 & -1.41 & TRUE & -1.41 \\
\hline NSEL & 1.82 & TRUE & 1.73 & 6 & TRUE & 6 & -1.83 & TRUE & -1.83 \\
\hline SSEL & 1.91 & TRUE & 1.81 & 5.83 & TRUE & 5.83 & -1.06 & TRUE & -0.79 \\
\hline $6 \mathrm{MC}$ & 0.97 & TRUE & 0.95 & 3.14 & TRUE & 3.14 & -0.31 & FALSE & -0.56 \\
\hline GYG & 0.73 & TRUE & 0.64 & 5.19 & TRUE & 5.19 & -1.24 & TRUE & -1.2 \\
\hline NMA & 0.14 & TRUE & 0.12 & 1.38 & TRUE & 1.38 & -1.14 & TRUE & -1.14 \\
\hline \multicolumn{10}{|c|}{ (d) Row Houses } \\
\hline & Average (NoEarly) & Left $>$ Right & Average (Early) & Max (NoEarly) & Left $>$ Right & Max (Early) & Min (NoEarly) & Left $>$ Right & Min (Early) \\
\hline SEL & 0.51 & TRUE & 0.31 & 7.33 & TRUE & 7.33 & -3.81 & TRUE & -3.81 \\
\hline NSEL & 0.42 & TRUE & 0.21 & 7.94 & TRUE & 7.94 & -3.89 & TRUE & -3.89 \\
\hline SSEL & 0.59 & TRUE & 0.33 & 6.67 & TRUE & 6.57 & -3.73 & TRUE & -3.73 \\
\hline $6 \mathrm{MC}$ & 0.61 & TRUE & 0.53 & 5.62 & TRUE & 5.62 & -1.53 & FALSE & -1.58 \\
\hline GYG & 0.65 & TRUE & 0.41 & 8.67 & TRUE & 8.67 & -4.45 & TRUE & -4.45 \\
\hline NMA & -0.09 & FALSE & -0.19 & 1.97 & TRUE & 1.79 & -2.32 & TRUE & -2.32 \\
\hline
\end{tabular}

Note: All numeric values are in percent(\%). NoEarly indicates the case of European option without an early exercise, whereas Early indicates the case of American option with the execution of early exercise. Left $>$ Right is true when the size of bubble in no early exercise is greater than that of early exercise. 
Then, we applied the same analysis to investigate a reduction in housing bubbles for different residential types and regions. In the case of apartments, the bubbles can be analyzed for a total of 13 different regions, which refers to the most detailed regional classification in this study. In this milieu, the average housing bubble was reduced in 11 regions, while the maximum and minimum were reduced in 12 and 11 regions, respectively. In the case of detached houses, the reductions of average and maximum housing bubbles were detected in all regions. However, those of the minimum were in five out of six regions. In the case of row houses, the reduction of the maximum housing bubble was detected in all regions, whereas those of average and minimum bubbles were in five out of six regions. In summary, the reductions of housing bubbles for all residential types could be observed in $85 \%$ of their regions.

Furthermore, we investigated the reduction of bubbles for different cross-sections, whose results are summarized in Table 14. From 2004 to 2008, the reduction of average bubbles in apartments was $12 \%(2.03 \% \rightarrow 1.78 \%)$, whereas that in row houses was $6 \%(3.07 \% \rightarrow 2.88 \%)$. The detached houses showed no reduction. The maximum bubbles were also reduced in all residential types, whereas the minimum bubbles were only reduced in detached houses. From 2009 to 2013, the reductions in average and minimum housing bubbles were not detected for all residential types. On the other hand, the reduction of the maximum bubble was detected in the apartment and detached house. From 2014 to 2018, the reductions of average and maximum bubbles were observed for all residential types, but no reduction was found in minimum bubbles.

Table 14. Comparisons for the cross-sectional bubbles with and without early exercise for different residential types.

\begin{tabular}{|c|c|c|c|c|c|c|c|c|c|}
\hline 2004-2008 & $\begin{array}{l}\text { Average } \\
\text { (NoEarly) }\end{array}$ & $\begin{array}{l}\text { Left > } \\
\text { Right }\end{array}$ & $\begin{array}{l}\text { Average } \\
\text { (Early) }\end{array}$ & $\begin{array}{l}\text { Max } \\
\text { (NoEarly) }\end{array}$ & $\begin{array}{l}\text { Left > } \\
\text { Right }\end{array}$ & $\begin{array}{l}\text { Max } \\
\text { (Early) }\end{array}$ & $\begin{array}{l}\text { Min } \\
\text { (NoEarly) }\end{array}$ & $\begin{array}{l}\text { Left > } \\
\text { Right }\end{array}$ & $\begin{array}{l}\text { Min } \\
\text { (Early) }\end{array}$ \\
\hline Apartments & 2.03 & TRUE & 1.78 & 5.16 & TRUE & 4.8 & -0.38 & FALSE & -0.56 \\
\hline Detached & 2.77 & FALSE & 2.77 & 4.03 & TRUE & 4.03 & 1.65 & TRUE & 1.54 \\
\hline Row & 3.07 & TRUE & 2.88 & 6.07 & TRUE & 6.02 & -0.18 & FALSE & -0.69 \\
\hline 2009-2013 & $\begin{array}{l}\text { Average } \\
\text { (NoEarly) }\end{array}$ & $\begin{array}{l}\text { Left > } \\
\text { Right }\end{array}$ & $\begin{array}{l}\text { Average } \\
\text { (Early) }\end{array}$ & $\begin{array}{l}\text { Max } \\
\text { (NoEarly) }\end{array}$ & $\begin{array}{l}\text { Left > } \\
\text { Right }\end{array}$ & $\begin{array}{l}\text { Max } \\
\text { (Early) }\end{array}$ & $\begin{array}{l}\text { Min } \\
\text { (NoEarly) }\end{array}$ & $\begin{array}{l}\text { Left > } \\
\text { Right }\end{array}$ & $\begin{array}{l}\text { Min } \\
\text { (Early) }\end{array}$ \\
\hline Apartments & -1.55 & FALSE & -1.7 & 2.32 & TRUE & 1.84 & -4.03 & FALSE & -4.04 \\
\hline Detached & -0.25 & FALSE & -0.38 & 0.94 & TRUE & 0.53 & -1.07 & FALSE & -1.1 \\
\hline Row & -1.85 & FALSE & -2.11 & 0.04 & FALSE & -0.93 & -3.01 & FALSE & -3.06 \\
\hline 2014-2018 & $\begin{array}{l}\text { Average } \\
\text { (NoEarly) }\end{array}$ & $\begin{array}{l}\text { Left }> \\
\text { Right }\end{array}$ & $\begin{array}{l}\text { Average } \\
\text { (Early) }\end{array}$ & $\begin{array}{l}\text { Max } \\
\text { (NoEarly) }\end{array}$ & $\begin{array}{l}\text { Left > } \\
\text { Right }\end{array}$ & $\begin{array}{l}\text { Max } \\
\text { (Early) }\end{array}$ & $\begin{array}{l}\text { Min } \\
\text { (NoEarly) }\end{array}$ & $\begin{array}{l}\text { Left > } \\
\text { Right }\end{array}$ & $\begin{array}{l}\text { Min } \\
\text { (Early) }\end{array}$ \\
\hline Apartments & 0.88 & TRUE & 0.81 & 5.19 & TRUE & 5.15 & -1.69 & FALSE & -1.75 \\
\hline Detached & 1.19 & TRUE & 1.12 & 3.6 & TRUE & 3.6 & -0.15 & FALSE & -0.18 \\
\hline Row & 0.12 & TRUE & 0.03 & 2.29 & TRUE & 2.24 & -1.56 & FALSE & -1.58 \\
\hline
\end{tabular}

Interestingly, all the cases of no reduction (i.e., that were false) possessed negative housing bubbles. A negative value in the housing bubble means that the Jeonse deposit is higher than the corresponding house price. Any amount of housing bubbles is possible in terms of present value, but such a situation is abnormal in the real market. Given that a Jeonse deposit refers only to its residential value, a house price is generally higher than a Jeonse deposit since it is the sum of the residential and investment values. Such a condition indicates the case of a negative investment value and difficulty in bubble reduction by early exercise. The same phenomenon can also be found in Table 13. Aside from exceptional cases where the average housing bubble is negative, in most cases, the reduction in housing bubbles can also be detected in different cross-sections. 
The reduction of bubbles for different cross-sections in apartments, and detached and row houses are summarized in Tables 15-17, respectively. In summary, the results are analogous to that of Table 14. Both cases with and without the reduction of the housing bubble are presented, and all cases of no reduction retain the negative housing bubbles. Hence, we confirm that the reductions of housing bubbles via early exercise for different cross-sections can be observed in all the cases of positive housing bubbles, which refer to the general market condition.

Table 15. Comparisons for the cross-sectional bubbles of apartments with and without early exercise.

\begin{tabular}{|c|c|c|c|c|c|c|c|c|c|}
\hline 2004-2008 & $\begin{array}{l}\text { Average } \\
\text { (NoEarly) }\end{array}$ & $\begin{array}{l}\text { Left > } \\
\text { Right }\end{array}$ & $\begin{array}{l}\text { Average } \\
\text { (Early) }\end{array}$ & $\begin{array}{l}\text { Max } \\
\text { (NoEarly) }\end{array}$ & $\begin{array}{l}\text { Left > } \\
\text { Right }\end{array}$ & $\begin{array}{l}\text { Max } \\
\text { (Early) }\end{array}$ & $\begin{array}{l}\text { Min } \\
\text { (NoEarly) }\end{array}$ & $\begin{array}{l}\text { Left }> \\
\text { Right }\end{array}$ & $\begin{array}{l}\text { Min } \\
\text { (Early) }\end{array}$ \\
\hline SEL & 5.57 & FALSE & 5.66 & 10.63 & TRUE & 10.63 & 1.32 & FALSE & 1.42 \\
\hline NSEL & 5.56 & TRUE & 5.32 & 10.87 & FALSE & 10.92 & 0.42 & TRUE & 0.1 \\
\hline SSEL & 5.49 & FALSE & 5.82 & 14.98 & TRUE & 14.98 & 1.38 & FALSE & 1.9 \\
\hline $6 \mathrm{MC}$ & 1.01 & TRUE & 0.76 & 1.83 & TRUE & 1.74 & 0.14 & FALSE & -0.42 \\
\hline GYG & 4.73 & TRUE & 4.47 & 11.8 & TRUE & 11.45 & 0.22 & TRUE & -0.2 \\
\hline GAW & 0.59 & TRUE & 0.26 & 1.75 & TRUE & 1.03 & -1.82 & TRUE & -1.82 \\
\hline ССВ & 0.72 & TRUE & 0.33 & 2.01 & TRUE & 1.5 & -0.99 & FALSE & -1.03 \\
\hline $\mathrm{CCN}$ & -0.09 & FALSE & -0.87 & 3.81 & TRUE & 2.63 & -2.3 & FALSE & -3.5 \\
\hline JLB & 0.87 & TRUE & 0.56 & 3.31 & TRUE & 2.65 & -0.46 & FALSE & -0.47 \\
\hline JLN & -0.28 & FALSE & -0.51 & 0.46 & FALSE & 0.7 & -1.02 & FALSE & -1.06 \\
\hline GSB & 1 & TRUE & 0.65 & 1.95 & TRUE & 1.26 & 0.03 & FALSE & -0.5 \\
\hline GSN & 0.59 & TRUE & 0.48 & 2.33 & TRUE & 2.27 & -1.15 & TRUE & -1.07 \\
\hline NMA & 0.58 & TRUE & 0.23 & 1.41 & TRUE & 0.64 & -0.67 & TRUE & -0.64 \\
\hline 2009-2013 & $\begin{array}{l}\text { Average } \\
\text { (NoEarly) }\end{array}$ & $\begin{array}{l}\text { Left > } \\
\text { Right }\end{array}$ & $\begin{array}{l}\text { Average } \\
\text { (Early) }\end{array}$ & $\begin{array}{l}\text { Max } \\
\text { (NoEarly) }\end{array}$ & $\begin{array}{l}\text { Left > } \\
\text { Right }\end{array}$ & $\begin{array}{l}\text { Max } \\
\text { (Early) }\end{array}$ & $\begin{array}{l}\text { Min } \\
\text { (NoEarly) }\end{array}$ & $\begin{array}{l}\text { Left }> \\
\text { Right }\end{array}$ & $\begin{array}{l}\text { Min } \\
\text { (Early) }\end{array}$ \\
\hline SEL & -5.45 & FALSE & -5.65 & -2.85 & FALSE & -3.84 & -7.21 & TRUE & -7.21 \\
\hline NSEL & -5.56 & FALSE & -5.75 & -3.12 & FALSE & -4.08 & -7.53 & TRUE & -7.53 \\
\hline SSEL & -5.43 & FALSE & -5.64 & -2.66 & FALSE & -3.74 & -7.05 & TRUE & -7.05 \\
\hline $6 \mathrm{MC}$ & -0.19 & FALSE & -0.33 & 5.23 & TRUE & 4.79 & -2.48 & FALSE & -2.66 \\
\hline GYG & -6.2 & FALSE & -6.43 & -4.54 & FALSE & -4.85 & -8 & TRUE & -8 \\
\hline GAW & -0.59 & FALSE & -0.98 & 3.19 & TRUE & 0.78 & -4.47 & TRUE & -4.47 \\
\hline ССВ & 0.46 & TRUE & 0.29 & 4.45 & TRUE & 3.46 & -1.43 & TRUE & -1.34 \\
\hline $\mathrm{CCN}$ & -1.03 & FALSE & -1.07 & -0.13 & FALSE & 1.12 & -2.42 & TRUE & -2.42 \\
\hline JLB & 1.04 & FALSE & 1.11 & 7.08 & TRUE & 6.51 & -3.61 & TRUE & -3.61 \\
\hline JLN & 0.37 & TRUE & 0.2 & 1.95 & FALSE & 2.66 & -1.98 & TRUE & -1.98 \\
\hline GSB & 0.26 & TRUE & 0.05 & 3.19 & TRUE & 3.19 & -1.84 & FALSE & -1.96 \\
\hline GSN & 1.55 & TRUE & 1.37 & 12.76 & TRUE & 12.76 & -2.64 & TRUE & -2.55 \\
\hline NMA & 0.65 & FALSE & 0.72 & 5.56 & TRUE & 5.11 & -1.69 & FALSE & -1.74 \\
\hline 2014-2018 & $\begin{array}{l}\text { Average } \\
\text { (NoEarly) }\end{array}$ & $\begin{array}{l}\text { Left > } \\
\text { Right }\end{array}$ & $\begin{array}{l}\text { Average } \\
\text { (Early) }\end{array}$ & $\begin{array}{l}\text { Max } \\
\text { (NoEarly) }\end{array}$ & $\begin{array}{l}\text { Left > } \\
\text { Right }\end{array}$ & $\begin{array}{l}\text { Max } \\
\text { (Early) }\end{array}$ & $\begin{array}{l}\text { Min } \\
\text { (NoEarly) }\end{array}$ & $\begin{array}{l}\text { Left > } \\
\text { Right }\end{array}$ & $\begin{array}{l}\text { Min } \\
\text { (Early) }\end{array}$ \\
\hline SEL & 3.73 & TRUE & 3.57 & 14.87 & TRUE & 14.87 & -1.62 & FALSE & -1.71 \\
\hline NSEL & 2.86 & TRUE & 2.68 & 13.27 & TRUE & 13.27 & -2.22 & TRUE & -2.22 \\
\hline SSEL & 4.37 & TRUE & 4.18 & 16.18 & TRUE & 16.18 & -1.22 & FALSE & -1.52 \\
\hline $6 \mathrm{MC}$ & 1.2 & TRUE & 1.15 & 3.15 & TRUE & 3.15 & 0.44 & TRUE & 0.32 \\
\hline GYG & 0.91 & TRUE & 0.76 & 4.74 & TRUE & 4.74 & -1.68 & FALSE & -1.71 \\
\hline GAW & 0.56 & TRUE & 0.49 & 1.71 & TRUE & 1.71 & -0.29 & FALSE & -0.55 \\
\hline ССВ & -0.64 & TRUE & -0.62 & 4.43 & TRUE & 4.43 & -3.45 & TRUE & -3.45 \\
\hline $\mathrm{CCN}$ & -0.37 & TRUE & -0.35 & 1.23 & TRUE & 0.96 & -1.36 & TRUE & -1.36 \\
\hline JLB & -0.54 & FALSE & -0.58 & 0.15 & TRUE & 0.13 & -1.15 & FALSE & -1.17 \\
\hline JLN & 0.15 & TRUE & 0.13 & 1.42 & TRUE & 1.42 & -1.39 & TRUE & -1.39 \\
\hline GSB & -0.12 & TRUE & -0.11 & 3.48 & TRUE & 3.48 & -2.7 & TRUE & -2.7 \\
\hline GSN & -0.53 & FALSE & -0.63 & 1.76 & TRUE & 1.58 & -3.49 & TRUE & -3.49 \\
\hline NMA & -0.19 & FALSE & -0.2 & 1.08 & TRUE & 1.06 & -1.81 & TRUE & -1.81 \\
\hline
\end{tabular}

Note: All numeric values are in percent(\%). NoEarly indicates the case of European option without an early exercise, whereas Early indicates the case of American option with the execution of early exercise. Left $>$ Right is true when the size of bubble in no early exercise is greater than that of early exercise. 
Table 16. Comparisons for the cross-sectional bubbles of detached houses between with and without early exercise.

\begin{tabular}{|c|c|c|c|c|c|c|c|c|c|}
\hline 2004-2008 & $\begin{array}{l}\text { Average } \\
\text { (NoEarly) } \\
\end{array}$ & $\begin{array}{l}\text { Left > } \\
\text { Right }\end{array}$ & $\begin{array}{l}\text { Average } \\
\text { (Early) }\end{array}$ & $\begin{array}{l}\text { Max } \\
\text { (NoEarly) } \\
\end{array}$ & $\begin{array}{l}\text { Left > } \\
\text { Right }\end{array}$ & $\begin{array}{l}\text { Max } \\
\text { (Early) }\end{array}$ & $\begin{array}{l}\text { Min } \\
\text { (NoEarly) }\end{array}$ & $\begin{array}{l}\text { Left > } \\
\text { Right }\end{array}$ & $\begin{array}{l}\text { Min } \\
\text { (Early) }\end{array}$ \\
\hline SEL & 4.55 & TRUE & 4.52 & 5.62 & TRUE & 5.62 & 3.33 & TRUE & 3.16 \\
\hline NSEL & 4.52 & TRUE & 4.5 & 6 & TRUE & 6 & 3.57 & TRUE & 3.49 \\
\hline SSEL & 4.59 & TRUE & 4.56 & 5.83 & TRUE & 5.83 & 2.79 & TRUE & 2.62 \\
\hline $6 \mathrm{MC}$ & 0.94 & FALSE & 0.94 & 1.66 & TRUE & 1.66 & 0.23 & FALSE & 0.26 \\
\hline GYG & 2.66 & FALSE & 2.68 & 5.19 & TRUE & 5.19 & 1.11 & TRUE & 0.84 \\
\hline NMA & -0.63 & TRUE & -0.56 & -0.13 & TRUE & -0.13 & -1.14 & TRUE & -1.14 \\
\hline $2009-2013$ & $\begin{array}{l}\text { Average } \\
\text { (NoEarly) }\end{array}$ & $\begin{array}{l}\text { Left > } \\
\text { Right }\end{array}$ & $\begin{array}{l}\text { Average } \\
\text { (Early) }\end{array}$ & $\begin{array}{l}\text { Max } \\
\text { (NoEarly) }\end{array}$ & $\begin{array}{l}\text { Left > } \\
\text { Right }\end{array}$ & $\begin{array}{l}\text { Max } \\
\text { (Early) }\end{array}$ & $\begin{array}{l}\text { Min } \\
\text { (NoEarly) }\end{array}$ & $\begin{array}{l}\text { Left > } \\
\text { Right }\end{array}$ & $\begin{array}{l}\text { Min } \\
\text { (Early) }\end{array}$ \\
\hline SEL & -0.36 & FALSE & -0.49 & 1.3 & TRUE & 0.8 & -1.41 & TRUE & -1.41 \\
\hline NSEL & -0.43 & FALSE & -0.56 & 1.72 & TRUE & 1.18 & -1.83 & TRUE & -1.83 \\
\hline SSEL & -0.23 & FALSE & -0.44 & 0.64 & TRUE & 0.3 & -1.06 & TRUE & -0.79 \\
\hline $6 \mathrm{MC}$ & 0.36 & TRUE & 0.29 & 1.01 & TRUE & 0.9 & -0.31 & FALSE & -0.56 \\
\hline GYG & -0.87 & FALSE & -1.04 & -0.12 & FALSE & -0.83 & -1.24 & TRUE & -1.2 \\
\hline NMA & 0.05 & FALSE & -0.08 & 1.08 & TRUE & 0.83 & -0.54 & FALSE & -0.81 \\
\hline 2014-2018 & $\begin{array}{l}\text { Average } \\
\text { (NoEarly) }\end{array}$ & $\begin{array}{l}\text { Left > } \\
\text { Right }\end{array}$ & $\begin{array}{l}\text { Average } \\
\text { (Early) }\end{array}$ & $\begin{array}{l}\text { Max } \\
\text { (NoEarly) }\end{array}$ & $\begin{array}{l}\text { Left > } \\
\text { Right }\end{array}$ & $\begin{array}{l}\text { Max } \\
\text { (Early) }\end{array}$ & $\begin{array}{l}\text { Min } \\
\text { (NoEarly) }\end{array}$ & $\begin{array}{l}\text { Left > } \\
\text { Right }\end{array}$ & $\begin{array}{l}\text { Min } \\
\text { (Early) }\end{array}$ \\
\hline SEL & 1.37 & TRUE & 1.29 & 5.19 & TRUE & 5.19 & -0.47 & TRUE & -0.47 \\
\hline NSEL & 1.36 & TRUE & 1.25 & 5.53 & TRUE & 5.53 & -0.7 & TRUE & -0.7 \\
\hline SSEL & 1.38 & TRUE & 1.29 & 4.64 & TRUE & 4.64 & -0.1 & FALSE & -0.25 \\
\hline $6 \mathrm{MC}$ & 1.61 & TRUE & 1.61 & 3.14 & TRUE & 3.14 & 0.58 & TRUE & 0.58 \\
\hline GYG & 0.38 & TRUE & 0.28 & 1.69 & TRUE & 1.69 & -0.62 & TRUE & -0.62 \\
\hline NMA & 1.01 & TRUE & 1.01 & 1.38 & TRUE & 1.38 & 0.41 & TRUE & 0.41 \\
\hline
\end{tabular}

Table 17. Comparisons for the cross-sectional bubbles of row houses between with and without early exercises.

\begin{tabular}{|c|c|c|c|c|c|c|c|c|c|}
\hline 2004-2008 & $\begin{array}{l}\text { Average } \\
\text { (NoEarly) }\end{array}$ & $\begin{array}{l}\text { Left > } \\
\text { Right }\end{array}$ & $\begin{array}{l}\text { Average } \\
\text { (Early) }\end{array}$ & $\begin{array}{l}\text { Max } \\
\text { (NoEarly) }\end{array}$ & $\begin{array}{l}\text { Left > } \\
\text { Right }\end{array}$ & $\begin{array}{l}\text { Max } \\
\text { (Early) }\end{array}$ & $\begin{array}{l}\text { Min } \\
\text { (NoEarly) }\end{array}$ & $\begin{array}{l}\text { Left > } \\
\text { Right }\end{array}$ & $\begin{array}{l}\text { Min } \\
\text { (Early) }\end{array}$ \\
\hline SEL & 4.31 & TRUE & 4.16 & 7.33 & TRUE & 7.33 & 0.79 & TRUE & 0.19 \\
\hline NSEL & 4.22 & TRUE & 4.05 & 7.94 & TRUE & 7.94 & 1.08 & TRUE & 0.53 \\
\hline SSEL & 4.4 & TRUE & 4.15 & 6.67 & TRUE & 6.57 & 0.51 & TRUE & -0.43 \\
\hline $6 \mathrm{MC}$ & 2.16 & TRUE & 2.12 & 5.62 & TRUE & 5.62 & -1.31 & TRUE & -1.31 \\
\hline GYG & 4.5 & TRUE & 4.08 & 8.67 & TRUE & 8.67 & 0.19 & FALSE & -0.8 \\
\hline NMA & -1.15 & FALSE & -1.26 & 0.21 & TRUE & -0.01 & -2.32 & TRUE & -2.32 \\
\hline 2009-2013 & $\begin{array}{l}\text { Average } \\
\text { (NoEarly) }\end{array}$ & $\begin{array}{l}\text { Left > } \\
\text { Right }\end{array}$ & $\begin{array}{l}\text { Average } \\
\text { (Early) }\end{array}$ & $\begin{array}{l}\text { Max } \\
\text { (NoEarly) }\end{array}$ & $\begin{array}{l}\text { Left > } \\
\text { Right }\end{array}$ & $\begin{array}{l}\text { Max } \\
\text { (Early) }\end{array}$ & $\begin{array}{l}\text { Min } \\
\text { (NoEarly) }\end{array}$ & $\begin{array}{l}\text { Left > } \\
\text { Right }\end{array}$ & $\begin{array}{l}\text { Min } \\
\text { (Early) }\end{array}$ \\
\hline SEL & -2.84 & FALSE & -3.16 & -0.92 & FALSE & -2.51 & -3.81 & TRUE & -3.81 \\
\hline NSEL & -2.84 & FALSE & -3.16 & -0.11 & FALSE & -1.69 & -3.89 & TRUE & -3.89 \\
\hline SSEL & -2.84 & FALSE & -3.21 & -1.74 & FALSE & -2.33 & -3.73 & TRUE & -3.73 \\
\hline $6 \mathrm{MC}$ & -0.65 & FALSE & -0.8 & 0.76 & TRUE & 0.2 & -1.53 & FALSE & -1.58 \\
\hline GYG & -2.5 & FALSE & -2.82 & 0.26 & FALSE & -1.03 & -4.45 & TRUE & -4.45 \\
\hline NMA & 0.6 & TRUE & 0.48 & 1.97 & TRUE & 1.79 & -0.65 & FALSE & -0.91 \\
\hline 2014-2018 & $\begin{array}{l}\text { Average } \\
\text { (NoEarly) }\end{array}$ & $\begin{array}{l}\text { Left > } \\
\text { Right }\end{array}$ & $\begin{array}{l}\text { Average } \\
\text { (Early) }\end{array}$ & $\begin{array}{l}\text { Max } \\
\text { (NoEarly) }\end{array}$ & $\begin{array}{l}\text { Left > } \\
\text { Right }\end{array}$ & $\begin{array}{l}\text { Max } \\
\text { (Early) }\end{array}$ & $\begin{array}{l}\text { Min } \\
\text { (NoEarly) }\end{array}$ & $\begin{array}{l}\text { Left > } \\
\text { Right }\end{array}$ & $\begin{array}{l}\text { Min } \\
\text { (Early) }\end{array}$ \\
\hline SEL & 0.05 & FALSE & -0.06 & 3.35 & TRUE & 3.29 & -2.25 & TRUE & -2.25 \\
\hline NSEL & -0.13 & FALSE & -0.26 & 3.05 & TRUE & 2.92 & -2.54 & TRUE & -2.54 \\
\hline SSEL & 0.21 & TRUE & 0.05 & 3.65 & TRUE & 3.53 & -1.99 & TRUE & -1.99 \\
\hline $6 \mathrm{MC}$ & 0.34 & TRUE & 0.26 & 0.78 & TRUE & 0.78 & -0.3 & FALSE & -0.44 \\
\hline GYG & -0.05 & TRUE & -0.03 & 2.07 & TRUE & 2.07 & -1.51 & TRUE & -1.51 \\
\hline NMA & 0.29 & TRUE & 0.21 & 0.86 & TRUE & 0.86 & -0.78 & TRUE & -0.74 \\
\hline
\end{tabular}

Note: All numeric values are in percent(\%). NoEarly indicates the case of European option without an early exercise, whereas Early indicates the case of American option with the execution of early exercise. Left $>$ Right is true when the size of bubble in no early exercise is greater than that of early exercise. 


\subsubsection{Effectiveness of Early Exercise and Shortened Contract Period}

Here, we also explore the effectiveness of an increased number of real estate transactions, along with the active early exercise based on the estimated present value. In order to artificially increase the number of transactions, we shortened the current minimum contract period of one year to six months to examine the arbitrage opportunity and the reduction of housing bubbles. Note that we allowed a direct extension of six months after the expiration of the previous six months' contract in order to not undermine the current policy and the tenant's residential stability. Of course, this attempt was only a simulation to increase the number of contracts artificially, and does not support the necessity of the shortened contract term.

Table 18A demonstrates the number of arbitrage opportunities, whereas Table 18B shows the size of the housing bubble for each residential type and trader's position. Note that the numbers in bold indicate superior frequency or size between the early and no early exercise. For detailed information regarding the long and short positions, please refer to the definition of the Jeonse system in Section 4.1 of [7]. For instance, the first row of Table 18A refers to the numbers of arbitrage opportunities of traders without the early exercise for all residential types based on 15 possible opportunities during the last 15 years. The number of short positions in the current 12 -month contract was 0.08 , whereas the number increased to 11.08 when the contract period was shortened to six months. Note that the decimal can exist in numbers since the total number of arbitrage opportunities was scaled into 15 transactions. The same result was found in a long position where the number was increased from 0.68 to 7.88. The second row of Table 18A is analogous to the first row, except that the numbers indicate the cases of early exercise. The results show that the number of arbitrage opportunities in both the short and long positions was increased from 0.88 to 13.68 and from 3.64 to 13.84 , respectively. Furthermore, the number of arbitrage opportunities was always higher when early exercise was executed. The same phenomenon was further detected in the apartments.

In contrast, a slightly different result was observed in the detached and row houses. In the existing 12-month contract without the early exercise, short-position traders received zero arbitrage opportunities in both the detached and row houses. This means that there was no arbitrage opportunity in selling the underlying real estate in any region for the past 15 years. It also implies the case of no bubble or no advantage in a short position concerning elapsed time in the contract. Therefore, the artificial increase in real estate transactions has a limited effect. Despite the 12-month contract without the early exercise, the number of arbitrage opportunities increased at any position when the early exercise was performed or the contract period was shortened.

The average size of a housing bubble per arbitrage opportunity, which can also be considered as the profit made from arbitrage trading, is summarized in Table 18B. The first row shows that the size of the housing bubble for a short position without early exercise in a 12-month contract is 1.2534 million KRW, whereas the bubble reduced to 1.1366 million KRW in a six-month contract. For a long position without early exercise, the size of the housing bubble in a 12-month contract is -2.7168 million KRW, whereas the bubble reduced to -1.0324 million KRW in a six-month contract. In addition, the execution of early exercise in the second row generates the reduction of bubbles, where the size of the bubble in both the short and long positions for the 12-month contract reduced to 0.3894 and -0.4241 million KRW, respectively. Also, the size of the bubble in both the short and long positions for the six-month contract reduced to 0.8102 and -0.3846 million KRW, respectively.

Furthermore, the reduction of bubbles through early exercise can be observed in all residential types and contract periods. On the other hand, the size of the housing bubble in a short position increases when the number of transactions increases through the shortened contract period. In conclusion, the number of arbitrage opportunities can be increased by both early exercise and the shortened contract period. However, the reduction of the size of the housing bubble is only obtained by early exercise. 
Table 18. Number of arbitrage opportunities and average size of housing bubbles for NoEarly \& early exercise in different residential types.

\begin{tabular}{|c|c|c|c|c|c|}
\hline \multicolumn{6}{|c|}{ (A) Number of Arbitrage Opportunities } \\
\hline & & $\begin{array}{l}\text { Arbitrage } \\
\text { (12 M/Short) }\end{array}$ & $\begin{array}{l}\text { Arbitrage } \\
\text { (6 M/Short) }\end{array}$ & $\begin{array}{l}\text { Arbitrage } \\
\text { (6 M/Long) }\end{array}$ & $\begin{array}{l}\text { Arbitrage } \\
\text { (12 M/Long) }\end{array}$ \\
\hline \multirow[t]{2}{*}{ All Types } & NoEarly & 0.08 & 11.08 & 7.88 & 0.68 \\
\hline & Early & 0.88 & 13.68 & 13.84 & 3.64 \\
\hline \multirow{2}{*}{ Apartments } & NoEarly & 0.15 & 10.69 & 8.62 & 1 \\
\hline & Early & 0.85 & 13.54 & 14.46 & 3.62 \\
\hline \multirow[t]{2}{*}{ Detached } & NoEarly & 0 & 12.17 & 6.17 & 0.17 \\
\hline & Early & 1.67 & 14.67 & 11.5 & 3.5 \\
\hline \multirow[t]{2}{*}{ Row } & NoEarly & 0 & 10.83 & 8 & 0.5 \\
\hline & Early & 0.17 & 13 & 14.83 & 3.83 \\
\hline \multicolumn{6}{|c|}{ (B) Average Size of housing bubbles Per An Arbitrage } \\
\hline & & $\begin{array}{l}\text { Arbitrage } \\
\text { (12 M/Short) }\end{array}$ & $\begin{array}{l}\text { Arbitrage } \\
\text { (6 M/Short) }\end{array}$ & $\begin{array}{l}\text { Arbitrage } \\
\text { (6 M/Long) }\end{array}$ & $\begin{array}{l}\text { Arbitrage } \\
\text { (12 M/Long) }\end{array}$ \\
\hline \multirow[t]{2}{*}{ All Types } & NoEarly & 125.34 & 113.66 & -103.24 & -271.68 \\
\hline & Early & 38.94 & 81.02 & -38.46 & -42.41 \\
\hline \multirow[t]{2}{*}{ Apartments } & NoEarly & 125.34 & 137.01 & -131.59 & -295.57 \\
\hline & Early & 34.89 & 94.62 & -50.16 & -57.29 \\
\hline \multirow[t]{2}{*}{ Detached } & NoEarly & nan & 120.75 & -71.08 & -52.95 \\
\hline & Early & 46.9 & 89.16 & -29.49 & -29.94 \\
\hline \multirow[t]{2}{*}{ Row } & NoEarly & nan & 55.76 & -61.9 & -241.04 \\
\hline & Early & 3.91 & 41.15 & -20.72 & -23.39 \\
\hline
\end{tabular}

Note: $12 \mathrm{M}, 6 \mathrm{M}$, Short, and Long are abbreviations for 12 months, 6 months, short position, and long position, respectively. The unit of numbers in lower table is ten thousands KRW, respectively.

Specifically, the results of Table 18 are the averages of the frequencies of arbitrage opportunities and the sizes of housing bubbles in different regions. The detailed results for the number of arbitrage opportunities and size of housing bubbles on cases of without and with early exercise are listed in Tables 19 and 20, respectively. Note that the numbers in Tables 19B and 20B indicate the sum of housing bubbles for all the arbitrage opportunities for each residential type and region. Analogous to the results in Table 18, Tables 19 and 20 also present the increases in arbitrage opportunities and decreases in the size of housing bubbles due to the early exercise and shortened contract period. Therefore, we conclude that both the utilizations of early exercise and increased trading volume are effective in reducing bubbles in the Korean real estate market. Besides, early exercise is more effective than increased trading volume at reducing the housing bubbles.

Table 19. Number of arbitrage opportunities and size of housing bubbles without early exercise in different residential types and regions.

\begin{tabular}{lllll}
\hline \multicolumn{2}{c}{ (A) Number of Arbitrage Opportunities } & \\
\hline & $\begin{array}{l}\text { Arbitrage } \\
(\mathbf{1 2} \text { M/Short) }\end{array}$ & $\begin{array}{l}\text { Arbitrage } \\
\text { (6 M/Short) }\end{array}$ & $\begin{array}{l}\text { Arbitrage } \\
\text { (6 M/Long) }\end{array}$ & $\begin{array}{l}\text { Arbitrage } \\
\text { (12 M/Long) }\end{array}$ \\
\hline SEL-Apartments & 0 & 10 & 6 & 2 \\
SEL-Detached & 0 & 12 & 6 & 0 \\
SEL-Row & 0 & 10 & 7 & 1 \\
NSEL-Apartments & 0 & 10 & 7 & 1 \\
NSEL-Detached & 0 & 12 & 6 & 0 \\
NSEL-Row & 0 & 10 & 7 & 1 \\
SSEL-Apartments & 0 & 10 & 6 & 2 \\
SSEL-Detached & 0 & 14 & 6 & 0 \\
SSEL-Row & 0 & 10 & 7 & 1 \\
6MC-Apartments & 0 & 14 & 6 & 0 \\
6MC-Detached & 0 & 15 & 3 & 0 \\
6MC-Row & 0 & 13 & 9 & 1 \\
GYG-Apartments & 0 & 10 & 7 & 1 \\
GYG-Detached & 0 & 11 & 6 & 0 \\
GYG-Row & 0 & 11 & 7 & 0 \\
GAW-Apartments & 0 & 13 & 10 & 1 \\
CCB-Apartments & 1 & 9 & 10 & 1 \\
CCN-Apartments & 0 & 6 & 14 & 2 \\
JLB-Apartments & 0 & 12 & 9 & 1 \\
JLN-Apartments & 0 & 11 & 9 & \\
\hline
\end{tabular}


Table 19. Cont.

\begin{tabular}{|c|c|c|c|c|}
\hline \multicolumn{5}{|c|}{ (A) Number of Arbitrage Opportunities } \\
\hline & $\begin{array}{l}\text { Arbitrage } \\
\text { (12 M/Short) }\end{array}$ & $\begin{array}{l}\text { Arbitrage } \\
\text { (6 M/Short) }\end{array}$ & $\begin{array}{l}\text { Arbitrage } \\
\text { (6 M/Long) }\end{array}$ & $\begin{array}{l}\text { Arbitrage } \\
\text { (12 M/Long) }\end{array}$ \\
\hline GSB-Apartments & 1 & 11 & 5 & 2 \\
\hline GSN-Apartments & 0 & 11 & 12 & 0 \\
\hline NMA-Apartments & 0 & 12 & 11 & 0 \\
\hline NMA-Detached & 0 & 9 & 10 & 0 \\
\hline NMA-Row & 0 & 11 & 11 & 0 \\
\hline \multicolumn{5}{|c|}{ (B) Size of housing bubbles } \\
\hline & $\begin{array}{l}\text { Arbitrage } \\
\text { (12 M/Short) }\end{array}$ & $\begin{array}{l}\text { Arbitrage } \\
\text { (6 M/Short) }\end{array}$ & $\begin{array}{l}\text { Arbitrage } \\
\text { (6 M/Long) }\end{array}$ & $\begin{array}{l}\text { Arbitrage } \\
\text { (12 M/Long) }\end{array}$ \\
\hline SEL-Apartments & 0 & 4763.82 & -3551.91 & -1177.04 \\
\hline SEL-Detached & 0 & 2492.01 & -677.54 & 0 \\
\hline SEL-Row & 0 & 951.45 & -786.9 & -225.74 \\
\hline NSEL-Apartments & 0 & 3378.62 & -2703.18 & -697.93 \\
\hline NSEL_Detached & 0 & 2231.33 & -746.78 & 0 \\
\hline NSEL-Row & 0 & 835.48 & -756.58 & -24.04 \\
\hline SSEL-Apartments & 0 & 6382.05 & -4275.05 & -1226.58 \\
\hline SSEL_Detached & 0 & 2560.89 & -530.96 & 0 \\
\hline SSEL-Row & 0 & 1095.99 & -812.36 & -473.34 \\
\hline 6MC-Apartments & 0 & 451.71 & -372.6 & 0 \\
\hline 6MC-Detached & 0 & 355.73 & -73.43 & 0 \\
\hline 6MC-Row & 0 & 182.62 & -110.67 & 0 \\
\hline GYG-Apartments & 0 & 1530.54 & -1987.32 & -119.93 \\
\hline GYG-Detached & 0 & 979.48 & -493.1 & -52.95 \\
\hline GYG-Row & 0 & 487.98 & -416.73 & 0 \\
\hline GAW-Apartments & 0 & 229.96 & -230.85 & 0 \\
\hline ССВ-Apartments & 100.48 & 399.82 & -266.91 & -19.91 \\
\hline $\mathrm{CCN}$-Apartments & 0 & 275.33 & -238.57 & -25.61 \\
\hline JLB-Apartments & 0 & 341.46 & -200.97 & -187.86 \\
\hline JLN-Apartments & 0 & 156.96 & -156.37 & -62.96 \\
\hline GSB_-Apartments & 150.21 & 267.05 & -292.47 & -324.6 \\
\hline GSN-Apartments & 0 & 598 & -298.56 & 0 \\
\hline NMA-Apartments & 0 & 268.68 & -162.75 & 0 \\
\hline NMA-Detached & 0 & 195.66 & -108.23 & 0 \\
\hline NMA-Row & 0 & 70.8 & -87.88 & 0 \\
\hline
\end{tabular}

Note: 12 M, $6 \mathrm{M}$, Short, and Long are abbreviations for 12 months, 6 months, short position, and long position, respectively. The unit of numbers in lower table is ten thousands KRW, respectively.

Table 20. Number of arbitrage opportunities and size of housing bubbles with early exercise in different residential types and regions.

\begin{tabular}{|c|c|c|c|c|}
\hline \multicolumn{5}{|c|}{ (A) Number of Arbitrage Opportunities } \\
\hline & $\begin{array}{l}\text { Arbitrage } \\
\text { (12 M/Short) }\end{array}$ & $\begin{array}{l}\text { Arbitrage } \\
\text { (6 M/Short) }\end{array}$ & $\begin{array}{l}\text { Arbitrage } \\
\text { (6 M/Long) }\end{array}$ & $\begin{array}{l}\text { Arbitrage } \\
\text { (12 M/Long) }\end{array}$ \\
\hline SEL-Apartments & 0 & 12 & 11 & 3 \\
\hline SEL-Detached & 3 & 15 & 10 & 3 \\
\hline SEL-Row & 0 & 12 & 15 & 5 \\
\hline NSEL-Apartments & 0 & 12 & 13 & 3 \\
\hline NSEL-Detached & 1 & 13 & 11 & 4 \\
\hline NSEL-Row & 0 & 12 & 14 & 4 \\
\hline SSEL-Apartments & 0 & 12 & 13 & 2 \\
\hline SSEL-Detached & 3 & 16 & 12 & 5 \\
\hline SSEL-Row & 0 & 12 & 16 & 6 \\
\hline 6MC-Apartments & 1 & 15 & 14 & 3 \\
\hline 6MC-Detached & 0 & 16 & 8 & 4 \\
\hline 6MC-Row & 0 & 15 & 15 & 1 \\
\hline GYG-Apartments & 0 & 11 & 14 & 5 \\
\hline GYG-Detached & 1 & 13 & 15 & 5 \\
\hline GYG-Row & 0 & 12 & 13 & 3 \\
\hline GAW-Apartments & 2 & 15 & 16 & 4 \\
\hline CCB-Apartments & 1 & 13 & 15 & 5 \\
\hline $\mathrm{CCN}$-Apartments & 2 & 14 & 16 & 1 \\
\hline JLB-Apartments & 3 & 14 & 16 & 1 \\
\hline JLN-Apartments & 0 & 14 & 14 & 3 \\
\hline GSB-Apartments & 0 & 14 & 14 & 9 \\
\hline GSN-Apartments & 2 & 15 & 16 & 3 \\
\hline NMA-Apartments & 0 & 15 & 16 & 5 \\
\hline NMA-Detached & 2 & 15 & 13 & 0 \\
\hline NMA-Row & 1 & 15 & 16 & 4 \\
\hline
\end{tabular}


Table 20. Cont.

\begin{tabular}{|c|c|c|c|c|}
\hline \multicolumn{5}{|c|}{ (B) Size of housing bubbles } \\
\hline & $\begin{array}{l}\text { Arbitrage } \\
\text { (12 M/Short) }\end{array}$ & $\begin{array}{l}\text { Arbitrage } \\
\text { (6 M/Short) }\end{array}$ & $\begin{array}{l}\text { Arbitrage } \\
\text { (6 M/Long) }\end{array}$ & $\begin{array}{l}\text { Arbitrage } \\
\text { (12 M/Long) }\end{array}$ \\
\hline SEL-Apartments & 0 & 4114.95 & -2154.86 & -791.98 \\
\hline SEL-Detached & 27.7 & 2031.55 & -543.15 & -179.86 \\
\hline SEL-Row & 0 & 823.63 & -443.69 & -81.31 \\
\hline NSEL-Apartments & 0 & 2847.00 & -1689.40 & -186.6 \\
\hline NSEL_Detached & 63.44 & 2102.86 & -498.11 & -149.25 \\
\hline NSEL-Row & 0 & 731.82 & -452.75 & -162.18 \\
\hline SSEL-Apartments & 0 & 5641.41 & -2470.34 & -250.92 \\
\hline SSEL-Detached & 230.21 & 2323.76 & -472.52 & -106.31 \\
\hline SSEL-Row & 0 & 955.17 & -482.38 & -124.13 \\
\hline 6MC-Apartments & 87.43 & 430.23 & -246.61 & -94.42 \\
\hline 6MC-Detached & 0 & 345.76 & -95.33 & -76.71 \\
\hline 6MC-Row & 0 & 171.49 & -95.28 & -26.94 \\
\hline GYG-Apartments & 0 & 1454.07 & -1139.50 & -236.28 \\
\hline GYG-Detached & 57.23 & 906.27 & -310.8 & -116.69 \\
\hline GYG-Row & 0 & 466.12 & -289.66 & -107 \\
\hline GAW-Apartments & 43.13 & 248.54 & -236.54 & -133.3 \\
\hline $\mathrm{CCB}$-Apartments & 117.26 & 305.35 & -221.23 & -123.95 \\
\hline $\mathrm{CCN}$-Apartments & 9.55 & 197.13 & -304.92 & -277.27 \\
\hline JLB-Apartments & 93.36 & 320.4 & -206.11 & -85.09 \\
\hline JLN-Apartments & 0 & 170.29 & -189.61 & -230.7 \\
\hline GSB-Apartments & 0 & 236.24 & -148.63 & -124.9 \\
\hline GSN-Apartments & 33.12 & 452.59 & -265.23 & -70.87 \\
\hline NMA-Apartments & 0 & 235.68 & -156.71 & -86.25 \\
\hline NMA-Detached & 90.42 & 135.5 & -114.67 & 0 \\
\hline NMA-Row & 3.91 & 61.85 & -79.9 & -36.32 \\
\hline
\end{tabular}

Note: 12 M, 6 M, Short, and Long are abbreviations for 12 months, 6 months, short position, and long position, respectively. The unit of numbers in lower table is ten thousands KRW, respectively.

\section{Conclusions}

Throughout this paper, we defined the housing bubbles, explored the arbitrage opportunities, and investigated possible methods to reduce these bubbles by taking advantage of the detected arbitrage opportunities in the Korean real estate market. In our previous study, we proved that the proposed binomial option pricing model with heteroscedasticity, a Korea-specific model due to its unique leasing system called the Jeonse, can be utilized to measure the housing bubbles [7]. Since we only applied the model to the general housing indices representing the Korean real estate market as a whole, we extended the applications of the same approach to more detailed cases based on three residential types (apartments, and detached and row houses) and 13 regions (SEL, NSEL, SSEL, 6MC, GYG, GAW, CCB, CCN, JLB, JLN, GSB, GSN, and NMA). That is, in this paper, we attempted to confirm that the proposed model applies not only to a macroscopic reference, but also to microscopic regional applications.

At first, we discovered that the housing bubbles in the past 15 years were confirmed to realistically reflect trends in different residential types and regions. For example, the higher the population density and the closer the country's economic development plan, the higher the housing bubble. Also, the apartments, considered as a reliable asset and even an instrument for speculation due to its large trading volume, showed asymmetry between the positive and negative housing bubbles compared to other residential types.

Secondly, the breakdown of the past 15 years into three periods showed that the defined housing bubble changes over time due to underlying economic conditions. Specifically, the housing bubble is high when the economy and market conditions are robust, whereas the bubble is low during periods of economic crisis. The fact that the dependence on economic conditions varies in different residential types and regions implies that the segmented indices, rather than a simple macro housing index, are more effective at measuring housing bubbles in the Korean real estate market.

Lastly, we confirm that the activation of trade in the real estate market effectively reduces the housing bubbles. Note that the activation of trade is simulated in twofold: promotion of early exercise and a shortened contract period. In financial markets, the opportunity for arbitrage trading decreases 
as the transaction is activated, which reduces the profits that can be obtained with free lunch. The same phenomenon can be detected in the Korean real estate market. Both the promotion of early exercise and shortened contract period increase the number of arbitrage opportunities and reduces the size of bubbles in all residential types, regions, and periods. Notably, the promotion of early exercise is a more robust method in reducing the bubbles than the shortened contract period.

Our paper has the limitation of no consideration of transaction cost and tax, which should be addressed in a future study. Despite this limitation, we believe that this study still contributes to studies on the housing bubble in Korea. The collapse of a real estate bubble, such as the US sub-prime mortgage crisis, brought a significant negative impact on the economy. Consequently, the management of the housing bubble is the key to sustainable economic growth. In this regard, the promotion of early exercise and a shortened contract period which were presented in this paper can be utilized to reduce the bubble in the Korean real estate market. Therefore, the public announcement of measured bubbles and arbitrage opportunities in different residential types and regions can help in making rational investment decisions. Furthermore, a major obstacle that impedes the frequent real estate trade is the high costs involved in the contract. In particular, the real estate trade in Korea is highly dependent on agencies, which incurs the fixed costs in transaction fees. Therefore, based on our results, the introduction of a new real estate trading system that can solve such a problem (e.g., the recently proposed blockchain-based real estate ledger mechanism) can not only reduce the contract fees, but the housing bubbles also.

Author Contributions: This paper is to be attributed in equal parts to the authors. All authors have read and agreed to the published version of the manuscript.

Funding: This work was supported by the National Research Foundation of Korea (NRF) grant funded by the Ministry of Science and ICT (No. 2018R1C1B5043835).

Conflicts of Interest: The authors declare no conflict of interest.

\section{References}

1. Deng, Y.; Girardin, E.; Joyeux, R. Fundamentals and the volatility of real estate prices in China: A sequential modelling strategy. China Econ. Rev. 2018, 48, 205-222. [CrossRef]

2. Chung, H.S.; Kim, J.H. Housing speculation and housing price bubble in Korea. In KDI School of Public Policy $\mathcal{E}$ Management Paper; KDIS: Sejong-si, Korea, 2004.

3. Kim, B.H.; Min, H.G. Household lending, interest rates and housing price bubbles in Korea: regime switching model and Kalman filter approach. Econ. Model. 2011, 28, 1415-1423. [CrossRef]

4. Kim, K.H.; Lee, H.S. Real estate price bubble and price forecasts in Korea. In Proceedings of the Asia Real Estate Society Fifth Annual Conference, Beijing, China, 26-30 July 2000; pp. 26-30.

5. Bryant, S.K.; Kohn, J.W. A housing bubble debate resolved. J. Appl. Financ. Bank. 2013, 3, 55.

6. Kim, J.R.; Lim, G. Fundamentals and rational bubbles in the Korean housing market: A modified present-value approach. Econ. Model. 2016, 59, 174-181. [CrossRef]

7. Kim, K.; Song, J.W. Managing Bubbles in the Korean Real Estate Market: A Real Options Framework. Sustainability 2018, 10, 2875. [CrossRef]

8. Berkovec, J.A.; Goodman, J.L., Jr. Turnover as a measure of demand for existing homes. Real Estate Econ. 1996, 24, 421-440. [CrossRef]

9. Tu, Y.; Ong, S.E.; Han, Y.H. Turnovers and housing price dynamics: Evidence from Singapore condominium market. J. Real Estate Financ. Econ. 2009, 38, 254-274. [CrossRef]

10. Phillips, P.C.; Wu, Y.; Yu, J. Explosive behavior in the 1990s Nasdaq: When did exuberance escalate asset values? Int. Econ. Rev. 2011, 52, 201-226. [CrossRef]

11. Phillips, P.C.; Shi, S.; Yu, J. Specification sensitivity in right-tailed unit root testing for explosive behaviour. Oxf. Bull. Econ. Stat. 2014, 76, 315-333. [CrossRef]

12. Trigeorgis, L. Real options and interactions with financial flexibility. Financ. Manag. 1993, 22, $202-224$. [CrossRef] 
13. Busby, J.S.; Pitts, C. Real options in practice: an exploratory survey of how finance officers deal with flexibility in capital appraisal. Manag. Account. Res. 1997, 8, 169-186. [CrossRef]

14. Malpezzi, S.; Wachter, S. The role of speculation in real estate cycles. J. Real Estate Lit. 2005, 13, 141-164. [CrossRef]

15. Case, K.E.; Shiller, R.J.; Weiss, A.N. Index-Based Futures and Options Markets in Real Estate; Yale University: New Haven, CT, USA, 1991.

16. Buttimer, R.J., Jr.; Kau, J.B.; Slawson, V.C., Jr. A model for pricing securities dependent upon a real estate index. J. Hous. Econ. 1997, 6, 16-30. [CrossRef]

17. Fisher, J.D. New strategies for commercial real estate investment and risk management. J. Portf. Manag. 2005, 31, 154-161. [CrossRef]

18. Cunningham, C.R. Growth Controls, real options, and land development. Rev. Econ. Stat. 2007, 89, $343-358$. [CrossRef]

19. Foo Sing, T. Optimal timing of a real estate development under uncertainty. J. Prop. Invest. Financ. 2001, 19, 35-52. [CrossRef]

20. Plantinga, A.J.; Lubowski, R.N.; Stavins, R.N. The effects of potential land development on agricultural land prices. J. Urban Econ. 2002, 52, 561-581. [CrossRef]

21. Cunningham, C.R. House price uncertainty, timing of development, and vacant land prices: Evidence for real options in Seattle. J. Urban Econ. 2006, 59, 1-31. [CrossRef]

22. Wang, K.; Zhou, Y. Equilibrium real options exercise strategies with multiple players: The case of real estate markets. Real Estate Econ. 2006, 34, 1-49. [CrossRef]

23. Bulan, L.; Mayer, C.; Somerville, C.T. Irreversible investment, real options, and competition: Evidence from real estate development. J. Urban Econ. 2009, 65, 237-251. [CrossRef]

24. Cauley, S.D.; Pavlov, A.D. Rational delays: the case of real estate. J. Real Estate Financ. Econ. 2002, 24, 143-165. [CrossRef]

25. Ott, S.H.; Hughen, W.K.; Read, D.C. Optimal phasing and inventory decisions for large-scale residential development projects. J. Real Estate Financ. Econ. 2012, 45, 888-918. [CrossRef]

26. Hughen, W.K.; Read, D.C. Analyzing form-based zoning's potential to stimulate mixed-use development in different economic environments. Land Use Policy 2017, 61, 1-11. [CrossRef]

27. Myers, S.C. Determinants of corporate borrowing. J. Financ. Econ. 1977, 5, 147-175. [CrossRef]

28. Titman, S. Urban land prices under uncertainty. Am. Econ. Rev. 1985, 75, 505-514.

29. Power, G.J.; Turvey, C.G. US rural land value bubbles. Appl. Econ. Lett. 2010, 17, 649-656. [CrossRef]

30. Pavlov, A.D.; Wachter, S.M. Underpriced Lending and Real Estate Markets. Available online: https:/ / ssrn. com/abstract $=980298$ (accessed on 20 December 2006).

31. Pavlov, A.; Wachter, S. Mortgage put options and real estate markets. J. Real Estate Financ. Econ. 2009, $38,89$. [CrossRef]

32. Chiang, Y.H.; Joinkey So, C.K.; Stanley Yeung, C.W. Real option premium in Hong Kong land prices. J. Prop. Invest. Financ. 2006, 24, 239-258. [CrossRef]

33. Teng, H.J.; Chang, C.O.; Chau, K. Housing bubbles: A tale of two cities. Habitat Int. 2013, 39, 8-15. [CrossRef]

34. Yamazaki, R. Empirical testing of real option pricing models using Land Price Index in Japan. J. Prop. Invest. Financ. 2001, 19, 53-72. [CrossRef]

35. Yamaguchi, H.; Takezawa, N.; Sumita, U.; Azarmi, T. The Real Option Premium in Japanese Land Prices; Working Paper; International University of Japan: Niigata, Japan, 2000.

36. Čirjevskis, A.; Tatevosjans, E. Empirical Testing of Real Option in the Real Estate Market. Procedia Econ. Financ. 2015, 24, 50-59. [CrossRef]

37. Durica, M.; Guttenova, D.; Pinda, L.; Svabova, L. Sustainable Value of Investment in Real Estate: Real Options Approach. Sustainability 2018, 10, 4665. [CrossRef]

38. Regan, C.M.; Bryan, B.A.; Connor, J.D.; Meyer, W.S.; Ostendorf, B.; Zhu, Z.; Bao, C. Real options analysis for land use management: Methods, application, and implications for policy. J. Environ. Manag. 2015, 161, 144-152. [CrossRef] [PubMed]

39. Edeki, S.; Ugbebor, O.; Owoloko, E. Analytical solutions of the Black-Scholes pricing model for european option valuation via a projected differential transformation method. Entropy 2015, 17, 7510-7521. [CrossRef]

40. Vellekoop, M.H.; Nieuwenhuis, J.W. Efficient pricing of derivatives on assets with discrete dividends. Appl. Math. Financ. 2006, 13, 265-284. [CrossRef] 
41. Company, R.; Egorova, V.; Jódar, L.; Vázquez, C. Finite difference methods for pricing American put option with rationality parameter: Numerical analysis and computing. J. Comput. Appl. Math. 2016, 304, 1-17. [CrossRef]

42. Jeong, D.; Yoo, M.; Yoo, C.; Kim, J. A hybrid monte carlo and finite difference method for option pricing. Comput. Econ. 2019, 53, 111-124. [CrossRef]

43. Brennan, M.J.; Schwartz, E.S. Finite difference methods and jump processes arising in the pricing of Contingent claims: A synthesis. J. Financ. Quant. Anal. 1978, 13, 461-474. [CrossRef]

44. Hull, J.; White, A. Valuing derivative securities using the explicit finite difference method. J. Financ. Quant. Anal. 1990, 25, 87-100. [CrossRef]

45. O'Sullivan, S.; O'Sullivan, C. On the acceleration of explicit finite difference methods for option pricing. Quant. Financ. 2011, 11, 1177-1191. [CrossRef]

46. Arciniega, A.; Allen, E. Extrapolation of difference methods in option valuation. Appl. Math. Comput. 2004, 153, 165-186. [CrossRef]

47. Zvan, R.; Forsyth, P.A.; Vetzal, K. A finite volume approach for Contingent claims valuation. IMA J. Numer. Anal. 2001, 21, 703-731. [CrossRef]

48. Tangman, D.; Gopaul, A.; Bhuruth, M. A fast high-order finite difference algorithm for pricing American options. J. Comput. Appl. Math. 2008, 222, 17-29. [CrossRef]

49. Nielsen, B.F.; Skavhaug, O.; Tveito, A. Penalty methods for the numerical solution of American multi-asset option problems. J. Comput. Appl. Math. 2008, 222, 3-16. [CrossRef]

50. Cox, J.C.; Ross, S.A.; Rubinstein, M. Option pricing: A simplified approach. J. Financ. Econ. 1979, 7, $229-263$. [CrossRef]

51. Broadie, M.; Detemple, J. American option valuation: New bounds, approximations, and a comparison of existing methods. Rev. Financ. Stud. 1996, 9, 1211-1250. [CrossRef]

52. Gaudenzi, M.; Pressacco, F. An efficient binomial method for pricing American options. Decis. Econ. Financ. 2003, 26, 1-17. [CrossRef]

53. Schwert, G.W. Why does stock market volatility change over time? J. Financ. 1989, 44, 1115-1153. [CrossRef]

54. Engle, R.F.; Rangel, J.G. The spline-GARCH model for low-frequency volatility and its global macroeconomic causes. Rev. Financ. Stud. 2008, 21, 1187-1222. [CrossRef]

55. Dolde, W.; Tirtiroglu, D. Temporal and spatial information diffusion in real estate price changes and variances. Real Estate Econ. 1997, 25, 539-565. [CrossRef]

56. Crawford, G.W.; Fratantoni, M.C. Assessing the forecasting performance of regime-switching, ARIMA and GARCH models of house prices. Real Estate Econ. 2003, 31, 223-243. [CrossRef]

57. Miller, N.; Peng, L. Exploring metropolitan housing price volatility. J. Real Estate Financ. Econ. 2006, 33, 5-18. [CrossRef]

58. Miles, W. Volatility clustering in US home prices. J. Real Estate Res. 2008, 30, 73-90.

59. Duan, J.C. The GARCH option pricing model. Math. Financ. 1995, 5, 13-32. [CrossRef]

60. Ritchken, P.; Trevor, R. Pricing options under generalized GARCH and stochastic volatility processes. J. Financ. 1999, 54, 377-402. [CrossRef]

61. Barone-Adesi, G.; Engle, R.F.; Mancini, L. A GARCH option pricing model with filtered historical simulation. Rev. Financ. Stud. 2008, 21, 1223-1258. [CrossRef]

62. Lehar, A.; Scheicher, M.; Schittenkopf, C. GARCH vs. stochastic volatility: Option pricing and risk management. J. Bank. Financ. 2002, 26, 323-345. [CrossRef]

63. Lehnert, T. Explaining smiles: GARCH option pricing with conditional leptokurtosis and skewness. J. Deriv. 2003, 10, 27-39. [CrossRef]

64. Brooks, R.; Chance, D.M.; Cline, B. Private information and the exercise of executive stock options. Financ. Manag. 2012, 41, 733-764. [CrossRef]

65. Tubetov, D.; Christin Maart-Noelck, S.; Musshoff, O. Real options or net present value? An experimental approach on the investment behavior of Kazakhstani and German farmers. Agric. Financ. Rev. 2013, 73, $426-457$. [CrossRef]

66. Bensoussan, A. On the theory of option pricing. Acta Appl. Math. 1984, 2, 139-158.

67. Beibel, M.; Lerche, H.R. A new look at optimal stopping problems related to mathematical finance. Stat. Sin. 1997, 7, 93-108. 
68. Geltner, D.; Miller, N.G.; Clayton, J.; Eichholtz, P. Commercial Real Estate Analysis and Investments; South-Western Publishing: Cincinnati, OH, USA, 2001; Volume 1.

69. Merton, R.C.; Bodie, Z. Design of financial systems: Towards a synthesis of function and structure. In The World Of Risk Management; World Scientific: Singapore, 2006; pp. 1-27.

70. Ambrose, B.W.; Kim, S. Modeling the Korean Chonsei lease Contract. Real Estate Econ. 2003, 31, 53-74. [CrossRef]

71. Brandão, L.E.; Dyer, J.S.; Hahn, W.J. Using binomial decision trees to solve real-option valuation problems. Decis. Anal. 2005, 2, 69-88. [CrossRef]

72. Brandão, L.E.; Dyer, J.S. Decision analysis and real options: A discrete time approach to real option valuation. Ann. Oper. Res. 2005, 135, 21-39. [CrossRef]

73. Alexander, D.R.; Mo, M.; Stent, A.F. Arithmetic Brownian motion and real options. Eur. J. Oper. Res. 2012, 219, 114-122. [CrossRef]

74. Yuen, F.L.; Yang, H. Option pricing with regime switching by trinomial tree method. J. Comput. Appl. Math. 2010, 233, 1821-1833. [CrossRef]

75. Haahtela, T.J. Recombining Trinomial Tree for Real Option Valuation with Changing Volatility. Available online: https: / / ssrn.com/abstract=1932411 (accessed on 29 April 2010).

76. Girsanov, I.V. On transforming a certain class of stochastic processes by absolutely Continuous substitution of measures. Theory Probab. Its Appl. 1960, 5, 285-301. [CrossRef]

77. Nelson, D.B. Stationarity and persistence in the GARCH $(1,1)$ model. Econom. Theory 1990, 6, 318-334. [CrossRef]

78. Lee, S.W.; Hansen, B.E. Asymptotic theory for the GARCH $(1,1)$ quasi-maximum likelihood estimator. Econom. Theory 1994, 10, 29-52. [CrossRef]

79. Mikosch, T.; Starica, C. Limit theory for the sample autocorrelations and extremes of a GARCH $(1,1)$ process. Ann. Stat. 2000, 28, 1427-1451.

80. Ling, S.; McAleer, M. Stationarity and the existence of moments of a family of GARCH processes. J. Econom. 2002, 106, 109-117. [CrossRef]

81. Duan, J.C. Augmented GARCH (p, q) process and its diffusion limit. J. Econom. 1997, 79, 97-127. [CrossRef]

82. Hansen, P.R.; Lunde, A. A forecast comparison of volatility models: does anything beat a GARCH $(1,1)$ ? J. Appl. Econom. 2005, 20, 873-889. [CrossRef]

83. Lavielle, M.; Teyssiere, G. Adaptive detection of multiple change-points in asset price volatility. In Long Memory in Economics; Springer: Berlin/Heidelberg, Germany, 2007; pp. 129-156. 